\title{
Plasma Reactors and Plasma Thrusters Modeling by Ar Complete Global Models
}

\author{
Chloe Berenguer and Konstantinos Katsonis
}

DEDALOS Ltd, 54645 Thessaloniki, Greece

Correspondence should be addressed to Konstantinos Katsonis, katsonis.dedalos@gmail.com

Received 26 June 2012; Revised 14 September 2012; Accepted 20 September 2012

Academic Editor: I. D. Boyd

Copyright (C) 2012 C. Berenguer and K. Katsonis. This is an open access article distributed under the Creative Commons Attribution License, which permits unrestricted use, distribution, and reproduction in any medium, provided the original work is properly cited.

A complete global model for argon was developed and adapted to plasma reactor and plasma thruster modeling. It takes into consideration ground level and excited $\mathrm{Ar}$ and $\mathrm{Ar}^{+}$species and the reactor and thruster form factors. The electronic temperature, the species densities, and the ionization percentage, depending mainly on the pressure and the absorbed power, have been obtained and commented for various physical conditions.

\section{Introduction}

Global Models (GMs) which have been successful to describe low-pressure plasmas in Plasma Reactors (PRs) can also be used in modeling of Electric Propulsion (EP) and other devices. Study of PR and EP devices can be considerably assisted by using global model descriptions, because they are rather simple in comparison to cumbersome $\mathrm{PiC}$ models which constitute an elaborate alternative. Also, a GM often allows for a more straightforward physical explanation of the device functioning, an asset which is fundamental for its conception and optimization. Moreover, inclusion in the model of a rather extended chemical composition is somewhat simpler in the case of GM. However, description of the various species properties calls for an extended set of atomic data (AtD) to be included in the model. When this is the case, we are traditionally speaking of complete global model (CGM). Such models are used currently in studying various feeding options for advanced PR and EP technology, including mixtures of rare gas and molecular species.

Here, we focus on a study of two devices fed with pure argon. In case of molecular gases/mixtures, the data needed for the corresponding complete models, besides the atomic ones, encompass also parameters essential to describe important molecular processes encountered in PR and EP plasmas, such as molecular excitation-de-excitation, ionization, dissociation, and recombination.
The well-known basic equations of the CGM are the following balance equations.

(i) A power balance equation (PoBE) which describes the energy losses per electron-ion pair created and relates the absorbed power with the electronic density for a given electronic temperature. It includes losses coming from volume collisions and flows to the walls.

(ii) Particle balance equations (PaBEs), a set of equations, one for each species of which we calculate the population. They describe the kinetics of the present particles.

Following the physical situation, it may become necessary to resolve the set of equations (i) and (ii) together with the adequate equations describing the plasmas processes and overall discharge. For example, in the case of arcjet devices, Navier-Stokes equation has to be added to the set of equations (i) and (ii).

Data from collisional-radiative models (C-RMs), which we developed separately, are used here to write down the particle balance equations (PaBEs) of the CGM needed for the thruster characterization [1] and for a detailed plasma study based on the expected fuel constituents.

As we specifically consider Ar PR and Ar-fed EP devices, we take advantage of an extended Ar database, which is needed for optimizing the devices functioning. We had 
previously used some of these data in thruster and arcjet modeling $[2,3]$. Other Ar databases are also available; see, for example, [4] and references therein.

Once the characteristics of the devices are studied by using the AtD which are necessary to elaborate the CGM, the former may be monitored experimentally, mainly by emission spectroscopy and theoretically by comparison with the results (line intensities, electronic temperature $T_{e}$ ) obtained from "zero dimensional" C-RM models. C-RM are also useful for calculating the resonant VUV line intensities, which are cumbersome to measure. Moreover, they are used to evaluate the radiative plasma cooling and the erosion of the plasma facing components. Both become particularly important with increasing absorbed energy and functioning time [5].

In fact, an important part of the development of a CGM consists of determining the collisional energy losses per electron-ion pair created $\left(\varepsilon_{C}\right)$. In doing so, each type of energy loss is multiplied by its rate, and the sum is divided by the ionization rate. Note that $\varepsilon_{C}$ is also occasionally meant to represent the collisional energy losses per electrondouble ion pair created in collisions with simply ionized species. The $\varepsilon_{C}$ is essential for the power balance equation formulation, relating the electronic density $n_{e}$ to the input power as a function of the plasma constituents and of their energy losses due to collisions with electrons as a function of the $T_{e}$. For each atomic species, energy is mainly lost by elastic scattering (noted here ELAS), ionization (IONIZ), and excitation (EXC) processes. In molecular gas cases, specific energy losses are to be considered, as those due to vibrational excitation and dissociation $[4,6]$, the former being important for low energies and the latter for high ones. ELAS, IONIZ, and EXC have also been used as indexes for the reaction rates in Sections 2 and 3. Energy losses from the formed atoms and ions have also to be included in the PoBE. In the case of electronegative gases, negative ion formation must also be considered (see e.g., [7], page 82 ).

In the present argon CGM, we seek a Steady-State (SS) solution of a set of algebraic equations for the particle balance in addition to the PoBE equation. These are described in Section 2. Results obtained concerning neutral Ar I species populations in the ground level plus five averaged levels $(4 \mathrm{~s}(\mathrm{~m}), 4 \mathrm{~s}(\mathrm{t}), 4 \mathrm{p}, 3 \mathrm{~d}(\mathrm{p}-\mathrm{m})$, and $3 \mathrm{~d}(\mathrm{t}))$ are meant to represent the Ar I excited states. Two more averaged levels, $5 \mathrm{~s}(\mathrm{p}-\mathrm{m})$ and $5 s(t))$, are included in the PoBE equation, but, their population being too small, they have not been explicitly calculated. It has to be noted that the $s$ and $d$ configurations have been separated into transitory $(\mathrm{t})$, metastable $(\mathrm{m})$, and pseudometastable ( $\mathrm{p}-\mathrm{m})$ parts. A similar work has been made for the Ar II populations, but only populations of the $4 \mathrm{~s}(\mathrm{~m})$ and $4 \mathrm{~s}(\mathrm{t})$ averaged levels have been explicitly calculated. The specificity of the metastable levels has been clearly illustrated in both Ar I and Ar II cases. As discussed in Section 5, results that we obtain for the plasma reactors compare well with those available in the literature and notably those obtained by Kang et al. [4]. Besides, our CGM allows for critical comparison of experimental results in various working conditions.
Concerning the total density of species, we used the perfect gas law. Specifically, for the thruster plasma, we included the ion temperature $T_{\text {ions }}$ following an empirical correlation $T_{\mathrm{ions}} \approx T_{\mathrm{GAS}}+\left(0.5-T_{\mathrm{GAS}}\right) / p$; see, for example, [8]. No electron pressure was included, but electron losses to the wall or mantle have been taken into account.

In the following Section 2, we give the model description and some of its characteristics, before introducing in Section 3 the notion of the collisional energy losses in a choice of schemes representing the two typical cases of PR and EP. Then, the expected collisional energy losses from the neutral and ionized species of the argon are described in Section 4 and compared with those of the $\mathrm{N}_{2}$ molecule. Presentation and discussion of results obtained by application of the CGM in the cases of an Ar plasma reactor (Section 5) and of a helicon thruster (HT) fed with Ar follows (Section 6). As mentioned previously, we have sought only steady-state solutions of the system. As a result, the calculations are greatly simplified, without losing important characteristics of the devices functioning. In Section 7, we address the question of the used parameters sensitivity, together with some general considerations. Finally, conclusions and perspectives of this work are given in Section 8.

\section{Model Description and Characteristics for Ar Plasmas}

As was mentioned in the introduction, the model is composed of one power balance equation (PoBE) and of a system of particle balance equations ( $\mathrm{PaBEs}$ ). The PoBE giving the power dependence of the electron density is written in $\mathrm{cm}^{-3}$ as follows:

$$
n_{e}=\frac{P_{\mathrm{abs}}}{\left(e u_{B} \varepsilon_{T} A_{\mathrm{eff}}\right)} \quad\left(\mathrm{cm}^{-3}\right) .
$$

For Ar, the Bohm velocity $u_{B}$ is $u_{B, \mathrm{Ar}^{+}}=\left(e T_{e} / M_{\mathrm{Ar}}\right)^{1 / 2} ; \varepsilon_{T}$ is the total energy loss, $\varepsilon_{T}=\varepsilon_{i}+\varepsilon_{e}+\varepsilon_{C}$ with $\varepsilon_{i}$ and $\varepsilon_{e}$ the mean kinetic energy lost per ion and per electron, respectively, and $\varepsilon_{C}$ the energy lost by collisions of electrons with heavy particles; see [7]. All these have to be calculated here for the Ar case for the considered heavy particles, $\mathrm{Ar}$ and $\mathrm{Ar}^{+}$. Noting $\xi$ the ionization percentage and $\xi^{\prime}=(1-\xi)$ the percentage of neutrals, we obtain approximately

$$
n_{e}=\frac{P_{\mathrm{abs}}}{\left\{e u_{B, \mathrm{Ar}^{+}}\left(\varepsilon_{i}+\varepsilon_{e}+\xi^{\prime} \cdot \varepsilon_{C, \mathrm{Ar}}+\xi \cdot \varepsilon_{C, \mathrm{Ar}^{+}}\right) A_{\mathrm{eff}}\right\}} \quad\left(\mathrm{cm}^{-3}\right) .
$$

The area for effective loss $A_{\text {eff }}$ appearing in (1) and (2) is given by $A_{\text {eff }}=2 \pi\left(h_{L} R^{2}+h_{R} R L\right)$ with $R$ and $L$ the radius and length of the device and $h_{L}$ and $h_{R}$ the axial and radial edge to center ratios of positive ion density. A simplified form of ratios used previously for low and intermediate densities follows the formulation of Godyak, given in [7, p. 148]

$$
\begin{aligned}
& h_{R}=0.80\left[4+\left(\frac{R}{\lambda_{i}}\right)\right]^{-1 / 2}, \\
& h_{L}=0.86\left[3+\left(\frac{L}{2 \lambda_{i}}\right)\right]^{-1 / 2} .
\end{aligned}
$$


TABLE 1: Structure description of the averaged states of Ar I included in the CGM.

\begin{tabular}{|c|c|c|c|c|c|}
\hline \multicolumn{2}{|c|}{ Ionization energy $(\mathrm{eV})$} & \multicolumn{2}{|c|}{ Excitation energy $(\mathrm{eV})$} & \multicolumn{2}{|c|}{ Statistical weight } \\
\hline$\overline{E_{3 \mathrm{p}}^{I}}$ & 15.76 & & & $g_{3 \mathrm{p}}$ & 1. \\
\hline$E_{4 s, \mathrm{~m}}^{\mathrm{I}}$ & 4.18 & $E_{4 \mathrm{~s}, \mathrm{~m}}^{\mathrm{X}}$ & 11.58 & $g_{4 \mathrm{~s}, \mathrm{~m}}$ & 6. \\
\hline$E_{4 \mathrm{~s}, \mathrm{t}}^{\mathrm{I}}$ & 4.03 & $E_{4 s, t}^{\mathrm{X}}$ & 11.73 & $g_{4 \mathrm{~s}, \mathrm{t}}$ & 6. \\
\hline$E_{4 \mathrm{~s}}^{\mathrm{I}}$ & 4.11 & $E_{4 s}^{\mathrm{X}}$ & 11.65 & $g_{4 \mathrm{~s}}$ & 12. \\
\hline$E_{4 \mathrm{p}}^{\mathrm{I}}$ & 2.59 & $E_{4 \mathrm{p}}^{\mathrm{X}}$ & 13.17 & $g_{4 \mathrm{p}}$ & 36. \\
\hline$E_{3 \mathrm{~d}, \mathrm{~m}}^{\mathrm{I}}$ & 1.678 & $E_{3 \mathrm{~d}, \mathrm{~m}}^{\mathrm{X}}$ & 14.082 & $g_{3 \mathrm{~d}, \mathrm{~m}}$ & 51. \\
\hline$E_{3 \mathrm{~d}, \mathrm{t}}^{\mathrm{I}}$ & 1.653 & $E_{3 \mathrm{~d}, \mathrm{t}}^{\mathrm{X}}$ & 14.107 & $g_{3 \mathrm{~d}, \mathrm{t}}$ & 9. \\
\hline$E_{5 s, \mathrm{~m}}^{\mathrm{I}}$ & 1.663 & $E_{5 \mathrm{~s}, \mathrm{~m}}^{\mathrm{X}}$ & 14.097 & $g_{5 \mathrm{~s}, \mathrm{~m}}$ & 6. \\
\hline$E_{5 \mathrm{~s}, \mathrm{t}}^{\mathrm{I}}$ & 1.587 & $E_{5 \mathrm{~s}, \mathrm{t}}^{\mathrm{X}}$ & 14.173 & $g_{5 \mathrm{~s}, \mathrm{t}}$ & 6. \\
\hline
\end{tabular}

Here, convenient formulas joining the three regimes (low, intermediate and high pressure) have been used as given, for instance, in $[7,9]$. These formulas have been initially introduced by Lee and Lieberman [10]. In cylindrical geometry, they are

$$
\begin{gathered}
h_{R}=0.80\left[4+\left(\frac{R}{\lambda_{i}}\right)+\left(\frac{0.8 R u_{B}}{\chi_{01} J_{1}\left(\chi_{01}\right) D_{a}}\right)^{2}\right]^{-1 / 2}, \\
h_{L}=0.86\left[3+\left(\frac{L}{2 \lambda_{i}}\right)+\left(\frac{0.86 L u_{B}}{\pi D_{a}}\right)^{2}\right]^{-1 / 2},
\end{gathered}
$$

with $\lambda_{i}$ the mean free path of ions; for Ar, $\lambda_{i} \approx 3.03 \cdot 10^{-2} / p$ with $\lambda_{i}$ in $m$ and $p$ in mTorr [7]. $J_{1}(\chi)$ is the first-order Bessel function, and $\chi_{01}=2.405$ is the first zero of the $J_{0}$ Bessel function. The ambipolar diffusion coefficient $D_{a}$ is given by $D_{a}=D_{i}\left(1+T_{e} / T_{i}\right)$, with $D_{i}$ the diffusion coefficient for positive ions [7].

As for the PaBEs, each of them is constituted by the sum of all the creation and destruction terms for a given species $j$ and they can be written as

$$
\frac{d n_{j}}{d t}=\sum R_{\text {Production }}^{j}-\sum R_{\text {Loss }}^{j}
$$

where $\Sigma$ denotes the sum of all terms $R_{\text {Production }}^{j}$ and $R_{\text {Loss }}^{j}$ including the production and the loss rates involving the species $j$. Each reaction rate is given by the product of the reactant densities $n_{i}$ and the corresponding rate coefficient $k_{j}$ :

$$
R^{j}=k_{j} \cdot \prod_{i} n_{i} \quad\left(\mathrm{~cm}^{-3} \mathrm{~s}^{-1}\right)
$$

Note that for the gas flow, we used the formula given in [9] for Ar pumping into the reactor. Accordingly, the term of production of the Ar I GL by pumping gas into the chamber is written numerically as follows

$$
R_{\text {Production }}^{\text {ArGL }}=4.480 \cdot 10^{11} \cdot \frac{Q_{\mathrm{Ar}}}{V}\left(\mathrm{~cm}^{-3} \mathrm{~s}^{-1}\right) \text {, }
$$

for a flow rate $Q_{A r}$ in sccm, a volume $V$ in $m^{3}$, and a creation term $R_{\text {Production }}$ in $\mathrm{cm}^{-3} \mathrm{~s}^{-1}$. For the gas species pumped out from the reactor, we used the formula given in [4]. The loss term $R_{\text {Loss }}^{j}$ for a species $j$ can be written as

$$
R_{\text {Loss }}^{j}=\frac{1.378 \cdot 10^{5} \cdot Q_{\mathrm{Ar}} \cdot n_{j}}{\left(p_{\text {OUTLET }} \cdot V\right)}\left(\mathrm{cm}^{-3} \mathrm{~s}^{-1}\right),
$$

with $n_{j}$, the density of the species $j$ in $\mathrm{cm}^{-3}$, and poutLeT the outlet flow pressure in Torr. The outlet flow pressure is described for instance in [9] as the pressure situated at the other end of the outlet flow valve resulting from the increase or decrease of its aperture. $R_{\text {Loss }}^{j}$ is given in $\mathrm{cm}^{-3} \mathrm{~s}^{-1}, Q_{\mathrm{Ar}}$ is in sccm, and $V$ in $\mathrm{m}^{3}$ as in (7).

The entirety of the lists of the species and of the inelastic reactions considered in the model are given hereafter in Tables 1 to 5. Table 1 contains the structure data of Ar I, including the excitation and ionization energies and the statistical weights of the averaged levels of Ar I. Data belonging to the global $4 \mathrm{~s}$ configuration are also given for comparison. The list of the 23 processes included in the CGM, involving levels of the Ar I $4 \mathrm{~s}(\mathrm{~m}), 4 \mathrm{~s}(\mathrm{t})$ and $4 \mathrm{p}$ configurations, is given in Table 2. Here also, $(\mathrm{m})$ stands for metastable, $(\mathrm{t})$ for transitory, and ( $\mathrm{p}-\mathrm{m})$ for pseudometastable states. Note that elastic scattering rate is introduced only in the PoBE under $\mathcal{E}_{C}$ in order to determine the total energy losses together with those coming from the excitations and the ionization of the GL. All other reaction rates are separately included in the $\mathrm{PaBE}$ and participate to the determination of the populations coming from the system solution. Table 3 gives the list of the 23 processes involving $3 \mathrm{~d}$ levels included in the CGM, and processes involving states $5 \mathrm{~s}(\mathrm{~m})$ and $5 \mathrm{~s}(\mathrm{t})$ are given in Table 4. Processes involving Ar II species are in Table 5.

The necessary atomic data entering in (1) and (5) include transition probabilities and excitation and ionization rates. These have been separately calculated and/or evaluated using our standard computer codes and also available measurements [11]. To obtain the rate coefficients introduced in our CGM, the evaluated cross sections have been here integrated from threshold up to around $500 \mathrm{eV}$ over a Maxwellian distribution. In doing so, available elastic collision cross sections have been interpolated for higher collision energies. Rate coefficients have been parameterized with algebraic polynomials and are all valid in the range from 0.1 to $100 \mathrm{eV}$, as detailed in a recent publication [3]. Occasionally, these are noted by an index corresponding to the process, as is the case 
TABLE 2: Inelastic processes involving Ar I 4s and 4p levels.

\begin{tabular}{|c|c|c|}
\hline No. & Process & Description \\
\hline & & Ionization \\
\hline 1 & $\operatorname{Ar}(\mathrm{GL})+e^{-} \rightarrow \mathrm{Ar}^{+}+2 e^{-}$ & from the GL \\
\hline 2 & $\operatorname{Ar}(4 \mathrm{~s}, \mathrm{~m})+e^{-} \rightarrow \operatorname{Ar}^{+}+2 e^{-}$ & from the $4 \mathrm{~s}(\mathrm{~m})$ \\
\hline 3 & $\operatorname{Ar}(4 \mathrm{~s}, \mathrm{t})+e^{-} \rightarrow \mathrm{Ar}^{+}+2 e^{-}$ & from the $4 \mathrm{~s}(\mathrm{t})$ \\
\hline 4 & $\operatorname{Ar}(4 \mathrm{p})+e^{-} \rightarrow \operatorname{Ar}^{+}+2 e^{-}$ & from the $4 p$ \\
\hline & & Excitation of \\
\hline 5 & $\operatorname{Ar}(\mathrm{GL})+e^{-} \rightarrow \operatorname{Ar}(4 \mathrm{~s}, \mathrm{~m})+e^{-}$ & $\mathrm{GL} \rightarrow 4 \mathrm{~s}(\mathrm{~m})$ \\
\hline 6 & $\operatorname{Ar}(\mathrm{GL})+e^{-} \rightarrow \operatorname{Ar}(4 \mathrm{~s}, \mathrm{t})+e^{-}$ & $\mathrm{GL} \rightarrow 4 \mathrm{~s}(\mathrm{t})$ \\
\hline 7 & $\operatorname{Ar}(\mathrm{GL})+e^{-} \rightarrow \operatorname{Ar}(4 \mathrm{p})+e^{-}$ & $\mathrm{GL} \rightarrow 4 \mathrm{p}$ \\
\hline 8 & $\operatorname{Ar}(4 \mathrm{~s}, \mathrm{~m})+e^{-} \rightarrow \operatorname{Ar}(4 \mathrm{p})+e^{-}$ & $4 \mathrm{~s}(\mathrm{~m}) \rightarrow 4 \mathrm{p}$ \\
\hline 9 & $\operatorname{Ar}(4 \mathrm{~s}, \mathrm{t})+e^{-} \rightarrow \operatorname{Ar}(4 \mathrm{p})+e^{-}$ & $4 s(t) \rightarrow 4 p$ \\
\hline 10 & $\operatorname{Ar}(4 \mathrm{~s}, \mathrm{~m})+e^{-} \rightarrow \operatorname{Ar}(4 \mathrm{~s}, \mathrm{t})+e^{-}$ & $4 \mathrm{~s}(\mathrm{~m}) \rightarrow 4 \mathrm{~s}(\mathrm{t})$ \\
\hline & & De-excitation of \\
\hline 11 & $\operatorname{Ar}(4 \mathrm{~s}, \mathrm{t})+e^{-} \rightarrow \operatorname{Ar}(4 \mathrm{~s}, \mathrm{~m})+e^{-}$ & $4 \mathrm{~s}(\mathrm{t}) \rightarrow 4 \mathrm{~s}(\mathrm{~m})$ \\
\hline 12 & $\operatorname{Ar}(4 \mathrm{~s}, \mathrm{t})+e^{-} \rightarrow \operatorname{Ar}(\mathrm{GL})+e^{-}$ & $4 \mathrm{~s}(\mathrm{t}) \rightarrow \mathrm{GL}$ \\
\hline 13 & $\operatorname{Ar}(4 \mathrm{~s}, \mathrm{~m})+e^{-} \rightarrow \operatorname{Ar}(\mathrm{GL})+e^{-}$ & $4 \mathrm{~s}(\mathrm{~m}) \rightarrow \mathrm{GL}$ \\
\hline 14 & $\operatorname{Ar}(4 \mathrm{p})+e^{-} \rightarrow \operatorname{Ar}(\mathrm{GL})+e^{-}$ & $4 \mathrm{p} \rightarrow \mathrm{GL}$ \\
\hline 15 & $\operatorname{Ar}(4 \mathrm{p})+e^{-} \rightarrow \operatorname{Ar}(4 \mathrm{~s}, \mathrm{t})+e^{-}$ & $4 \mathrm{p} \rightarrow 4 \mathrm{~s}(\mathrm{t})$ \\
\hline 16 & $\operatorname{Ar}(4 \mathrm{p})+e^{-} \rightarrow \operatorname{Ar}(4 \mathrm{~s}, \mathrm{~m})+e^{-}$ & $4 \mathrm{p} \rightarrow 4 \mathrm{~s}(\mathrm{~m})$ \\
\hline & & Spontaneous emission \\
\hline 17 & $\operatorname{Ar}(4 s, t) \rightarrow \operatorname{Ar}(G L)+h \nu$ & $4 \mathrm{~s}(\mathrm{t}) \rightarrow \mathrm{GL}$ \\
\hline 18 & $\operatorname{Ar}(4 \mathrm{~s}, \mathrm{~m}) \rightarrow \operatorname{Ar}(\mathrm{GL})+h \nu$ & $4 \mathrm{~s}(\mathrm{~m}) \rightarrow \mathrm{GL}$ \\
\hline 19 & $\operatorname{Ar}(4 \mathrm{p}) \rightarrow \operatorname{Ar}(4 \mathrm{~s}, \mathrm{t})+h \nu$ & $4 \mathrm{p} \rightarrow 4 \mathrm{~s}(\mathrm{t})$ \\
\hline 20 & $\operatorname{Ar}(4 \mathrm{p}) \rightarrow \operatorname{Ar}(4 \mathrm{~s}, \mathrm{~m})+h \nu$ & $4 \mathrm{p} \rightarrow 4 \mathrm{~s}(\mathrm{~m})$ \\
\hline 21 & $\operatorname{Ar}(4 \mathrm{p})+$ wall $\rightarrow \operatorname{Ar}(\mathrm{GL})$ & $4 p$ de-excitation on the wall, see text \\
\hline 22 & $\operatorname{Ar}(4 s, t)+$ wall $\rightarrow \operatorname{Ar}(G L)$ & $4 \mathrm{~s}(\mathrm{t})$ de-excitation on the wall, see text \\
\hline 23 & $\operatorname{Ar}(4 s, m)+$ wall $\rightarrow \operatorname{Ar}(G L)$ & $4 \mathrm{~s}(\mathrm{~m})$ de-excitation on the wall, see text \\
\hline
\end{tabular}

in (6). Collisions with the wall (wall recombination RWALL, $\mathrm{Ar}^{+}$and de-excitation DXWALL, $j$ ) have rates described by formulas proposed in [12], as reported in [4] as follows:

$$
\begin{gathered}
k_{\mathrm{RWALL}, \mathrm{Ar}^{+}}=u_{B} \cdot \frac{A_{\mathrm{eff}}}{V} \quad\left(\mathrm{~s}^{-1}\right), \\
k_{\mathrm{DXWALL}, j}=\left[\frac{\Lambda^{2}}{D_{j}}+\frac{2 V\left(2-\gamma_{j}\right)}{A v_{j} \gamma_{j}}\right]^{-1} \quad\left(\mathrm{~s}^{-1}\right),
\end{gathered}
$$

with $\Lambda^{-2}=(\pi / L)^{2}+(2.405 / R)^{2}$, where $\Lambda$ is the effective diffusion length and $D_{j}$ the neutral diffusion coefficient, $D_{j}=\left(k_{B} T_{\mathrm{GAS}} \lambda_{j}\right) /\left(v_{j} M_{\mathrm{Ar}}\right) \cdot \lambda_{j}$ is the neutral-neutral species mean free path $\lambda_{j}=1 / n_{j} \sigma_{j+A r}$ for a cross section $\sigma, v_{j}$ is the neutral mean velocity, $v_{j}=\left(8 k_{B} T_{\mathrm{GAS}} / \pi M_{\mathrm{Ar}}\right)^{1 / 2}$, and $\gamma_{j}$ is the sticking coefficient for the neutral species $j$ on the wall surface; for Ar we used $\gamma=1$. Also, A stands for the wall surface area.

We have compared the results obtained with different sets of rate coefficients and for various configurations. Especially, when the transitory and metastable levels were separated, the metastable levels were found much more populated and playing an important role in the population of the bulk of the excited levels and hence in the plasma ionization.
A comparison of our $\varepsilon_{C}$ values with those coming from $[4,9,13]$ is given in Section 4 .

\section{Energy Losses from Electron Collisions in Various Devices}

In aerospace applications, as is for example the case of powerful plasma thrusters, the ionization percentage may become high, hence the collisional energy losses from the ions have also to be evaluated together with those coming from the neutrals. Inversely, whenever the ionization percentage is low (e.g., as in plasma reactors with ionization of about $1 \%$ or less), the energy losses due to ions can be neglected, when $T_{e}$ is not too high and pressure not too low.

Evaluation of the collisional losses in the Ar case, noted here $\varepsilon_{C, \mathrm{Ar}}$, follows the equation:

$$
\begin{aligned}
\varepsilon_{C, \mathrm{Ar}}= & E_{\mathrm{IONIZ,Ar}}+E_{\mathrm{ELAS}, \mathrm{Ar}} \frac{k_{\mathrm{ELAS}, \mathrm{Ar}}}{k_{\mathrm{IONIZ}, \mathrm{Ar}}} \\
& +\sum_{i} E_{\mathrm{EXC}, \mathrm{Ar}, i} \frac{k_{\mathrm{EXC}, \mathrm{Ar}, i}}{k_{\mathrm{IONIZ}, \mathrm{Ar}}}
\end{aligned}
$$

where the index Ar stands in principle for both neutral and ionized species. The $\varepsilon_{C \text {,Ar }}$ values which we obtained and 
TABLE 3: List of the processes involving Ar I 3d levels.

\begin{tabular}{|c|c|c|}
\hline No. & Process & Description \\
\hline & & Ionization \\
\hline 1 & $\operatorname{Ar}(3 \mathrm{~d}, \mathrm{p}-\mathrm{m})^{*}+e^{-} \rightarrow \mathrm{Ar}^{+}+2 e^{-}$ & from the $3 d(p-m)$ \\
\hline \multirow[t]{2}{*}{2} & $\operatorname{Ar}(3 \mathrm{~d}, \mathrm{t})+e^{-} \rightarrow \operatorname{Ar}^{+}+2 e^{-}$ & from the $3 \mathrm{~d}(\mathrm{t})$ \\
\hline & & Excitation \\
\hline 3 & $\operatorname{Ar}(\mathrm{GL})+e^{-} \rightarrow \operatorname{Ar}(3 \mathrm{~d}, \mathrm{p}-\mathrm{m})+e^{-}$ & $\mathrm{GL} \rightarrow 3 \mathrm{~d}(\mathrm{p}-\mathrm{m})$ \\
\hline 4 & $\operatorname{Ar}(\mathrm{GL})+e^{-} \rightarrow \operatorname{Ar}(3 \mathrm{~d}, \mathrm{t})+e^{-}$ & $\mathrm{GL} \rightarrow 3 \mathrm{~d}(\mathrm{t})$ \\
\hline 5 & $\operatorname{Ar}(4 \mathrm{~s}, \mathrm{~m})+e^{-} \rightarrow \operatorname{Ar}(3 \mathrm{~d}, \mathrm{p}-\mathrm{m})+e^{-}$ & $4 \mathrm{~s}(\mathrm{~m}) \rightarrow 3 \mathrm{~d}(\mathrm{p}-\mathrm{m})$ \\
\hline 6 & $\operatorname{Ar}(4 \mathrm{~s}, \mathrm{~m})+e^{-} \rightarrow \operatorname{Ar}(3 \mathrm{~d}, \mathrm{t})+e^{-}$ & $4 \mathrm{~s}(\mathrm{~m}) \rightarrow 3 \mathrm{~d}(\mathrm{t})$ \\
\hline 7 & $\operatorname{Ar}(4 \mathrm{~s}, \mathrm{t})+e^{-} \rightarrow \operatorname{Ar}(3 \mathrm{~d}, \mathrm{p}-\mathrm{m})+e^{-}$ & $4 \mathrm{~s}(\mathrm{t}) \rightarrow 3 \mathrm{~d}(\mathrm{p}-\mathrm{m})$ \\
\hline 8 & $\operatorname{Ar}(4 \mathrm{~s}, \mathrm{t})+e^{-} \rightarrow \operatorname{Ar}(3 \mathrm{~d}, \mathrm{t})+e^{-}$ & $4 \mathrm{~s}(\mathrm{t}) \rightarrow 3 \mathrm{~d}(\mathrm{t})$ \\
\hline 9 & $\operatorname{Ar}(4 \mathrm{p})+e^{-} \rightarrow \operatorname{Ar}(3 \mathrm{~d}, \mathrm{p}-\mathrm{m})+e^{-}$ & $4 p \rightarrow 3 d(p-m)$ \\
\hline 10 & $\operatorname{Ar}(4 \mathrm{p})+e^{-} \rightarrow \operatorname{Ar}(3 \mathrm{~d}, \mathrm{t})+e^{-}$ & $4 \mathrm{p} \rightarrow 3 \mathrm{~d}(\mathrm{t})$ \\
\hline \multirow[t]{2}{*}{11} & $\operatorname{Ar}(3 \mathrm{~d}, \mathrm{p}-\mathrm{m})+e^{-} \rightarrow \operatorname{Ar}(3 \mathrm{~d}, \mathrm{t})+e^{-}$ & $3 \mathrm{~d}(\mathrm{p}-\mathrm{m}) \rightarrow 3 \mathrm{~d}(\mathrm{t})$ \\
\hline & & De-excitation \\
\hline 12 & $\operatorname{Ar}(3 \mathrm{~d}, \mathrm{t})+e^{-} \rightarrow \operatorname{Ar}(3 \mathrm{~d}, \mathrm{p}-\mathrm{m})+e^{-}$ & $3 d(t) \rightarrow 3 d(p-m)$ \\
\hline 13 & $\operatorname{Ar}(3 \mathrm{~d}, \mathrm{t})+e^{-} \rightarrow \operatorname{Ar}(4 \mathrm{p})+e^{-}$ & $3 \mathrm{~d}(\mathrm{t}) \rightarrow 4 \mathrm{p}$ \\
\hline 14 & $\operatorname{Ar}(3 \mathrm{~d}, \mathrm{p}-\mathrm{m})+e^{-} \rightarrow \operatorname{Ar}(4 \mathrm{p})+e^{-}$ & $3 \mathrm{~d}(\mathrm{p}-\mathrm{m}) \rightarrow 4 \mathrm{p}$ \\
\hline 15 & $\operatorname{Ar}(3 \mathrm{~d}, \mathrm{t})+e^{-} \rightarrow \operatorname{Ar}(4 \mathrm{~s}, \mathrm{t})+e^{-}$ & $3 \mathrm{~d}(\mathrm{t}) \rightarrow 4 \mathrm{~s}(\mathrm{t})$ \\
\hline 16 & $\operatorname{Ar}(3 \mathrm{~d}, \mathrm{p}-\mathrm{m})+e^{-} \rightarrow \operatorname{Ar}(4 \mathrm{~s}, \mathrm{t})+e^{-}$ & $3 \mathrm{~d}(\mathrm{p}-\mathrm{m}) \rightarrow 4 \mathrm{~s}(\mathrm{t})$ \\
\hline 17 & $\operatorname{Ar}(3 \mathrm{~d}, \mathrm{t})+e^{-} \rightarrow \operatorname{Ar}(4 \mathrm{~s}, \mathrm{~m})+e^{-}$ & $3 \mathrm{~d}(\mathrm{t}) \rightarrow 4 \mathrm{~s}(\mathrm{~m})$ \\
\hline 18 & $\operatorname{Ar}(3 \mathrm{~d}, \mathrm{p}-\mathrm{m})+e^{-} \rightarrow \operatorname{Ar}(4 \mathrm{~s}, \mathrm{~m})+e^{-}$ & $3 \mathrm{~d}(\mathrm{p}-\mathrm{m}) \rightarrow 4 \mathrm{~s}(\mathrm{~m})$ \\
\hline 19 & $\operatorname{Ar}(3 \mathrm{~d}, \mathrm{t})+e^{-} \rightarrow \operatorname{Ar}(\mathrm{GL})+e^{-}$ & $3 \mathrm{~d}(\mathrm{t}) \rightarrow \mathrm{GL}$ \\
\hline \multirow[t]{2}{*}{20} & $\operatorname{Ar}(3 \mathrm{~d}, \mathrm{p}-\mathrm{m})+e^{-} \rightarrow \operatorname{Ar}(\mathrm{GL})+e^{-}$ & $3 \mathrm{~d}(\mathrm{p}-\mathrm{m}) \rightarrow \mathrm{GL}$ \\
\hline & & Spontaneous emission \\
\hline 21 & $\operatorname{Ar}(3 \mathrm{~d}, \mathrm{t}) \rightarrow \operatorname{Ar}(4 \mathrm{p})+h v$ & $3 \mathrm{~d}(\mathrm{t}) \rightarrow 4 \mathrm{p}$ \\
\hline 22 & $\operatorname{Ar}(3 \mathrm{~d}, \mathrm{p}-\mathrm{m}) \rightarrow \operatorname{Ar}(4 \mathrm{p})+h \nu$ & $3 \mathrm{~d}(\mathrm{p}-\mathrm{m}) \rightarrow 4 \mathrm{p}$ \\
\hline 23 & $\operatorname{Ar}(3 \mathrm{~d}, \mathrm{t}) \rightarrow \operatorname{Ar}(\mathrm{GL})+h v$ & $3 \mathrm{~d}(\mathrm{t}) \rightarrow \mathrm{GL}$ \\
\hline 24 & $\operatorname{Ar}(3 \mathrm{~d}, \mathrm{p}-\mathrm{m}) \rightarrow \operatorname{Ar}(\mathrm{GL})+h v$ & $3 \mathrm{~d}(\mathrm{p}-\mathrm{m}) \rightarrow \mathrm{GL}$ \\
\hline 25 & $\operatorname{Ar}(3 \mathrm{~d}, \mathrm{p}-\mathrm{m})+$ wall $\rightarrow \operatorname{Ar}(\mathrm{GL})$ & $3 \mathrm{~d}(\mathrm{p}-\mathrm{m})$ de-excitation on the wall \\
\hline 26 & $\operatorname{Ar}(3 \mathrm{~d}, \mathrm{t})+$ wall $\rightarrow \operatorname{Ar}(\mathrm{GL})$ & $3 \mathrm{~d}(\mathrm{t})$ de-excitation on the wall \\
\hline
\end{tabular}

${ }^{*}$ All 3d levels marked as (p-m) are in fact pseudometastable while all $4 \mathrm{~s}, \mathrm{~m}$ are real metastable ones.

TABLE 4: Inelastic processes involving Ar I 5s species.

\begin{tabular}{lll}
\hline No. & Process & Description \\
\hline 1 & $\operatorname{Ar}(\mathrm{GL})+e^{-} \rightarrow \operatorname{Ar}(5 \mathrm{~s}, \mathrm{p}-\mathrm{m})+e^{-}$ & Excitation GL $\rightarrow 5 \mathrm{~s}(\mathrm{p}-\mathrm{m})$ \\
2 & $\operatorname{Ar}(\mathrm{GL})+e^{-} \rightarrow \operatorname{Ar}(5 \mathrm{~s}, \mathrm{t})+e^{-}$ & Excitation GL $\rightarrow 5 \mathrm{~s}(\mathrm{t})$ \\
\hline
\end{tabular}

TABLE 5: Inelastic processes involving Ar II species.

\begin{tabular}{|c|c|c|}
\hline No. & Process & Description \\
\hline 1 & $\operatorname{Ar}^{+}(\mathrm{GL})+e^{-} \rightarrow \operatorname{Ar}^{++}(\mathrm{GL})+2 e^{-}$ & $\mathrm{Ar}^{+}$ionization \\
\hline 2 & $\operatorname{Ar}^{+}(\mathrm{GL})+e^{-} \leftrightarrow \operatorname{Ar}^{+}(4 \mathrm{~s}, \mathrm{~m})+e^{-}$ & (De-)Excitation Ar II GL↔4s(m) \\
\hline 3 & $\operatorname{Ar}^{+}(\mathrm{GL})+e^{-} \leftrightarrow \operatorname{Ar}^{+}(4 \mathrm{~s}, \mathrm{t})+e^{-}$ & (De-)Excitation Ar II GL $\leftrightarrow 4 \mathrm{~s}(\mathrm{t})$ \\
\hline 4 & $\operatorname{Ar}^{+}(\mathrm{GL})+e^{-} \rightarrow \operatorname{Ar}^{+}(3 \mathrm{~d})+e^{-}$ & Excitation Ar II GL $\rightarrow 3 \mathrm{~d}$ \\
\hline 5 & $\operatorname{Ar}^{+}(\mathrm{GL})+e^{-} \rightarrow \operatorname{Ar}^{+}(4 \mathrm{p})+e^{-}$ & Excitation Ar II GL $\rightarrow 4 p$ \\
\hline 6 & $\operatorname{Ar}^{+}(\mathrm{GL})+e^{-} \rightarrow \operatorname{Ar}^{+}(4 \mathrm{~d})+e^{-}$ & Excitation Ar II GL $\rightarrow 4 \mathrm{~d}$ \\
\hline 7 & $\operatorname{Ar}^{+}(4 \mathrm{~s}, \mathrm{t}) \rightarrow \operatorname{Ar}^{+}(\mathrm{GL})+h \nu$ & Spontaneous emission from Ar II $4 \mathrm{~s}(\mathrm{t})$ \\
\hline 8 & $\operatorname{Ar}^{+}(4 \mathrm{~s}, \mathrm{~m}) \rightarrow \operatorname{Ar}^{+}(\mathrm{GL})+h v$ & Spontaneous emission from $\mathrm{Ar}$ II $4 \mathrm{~s}(\mathrm{~m})$ \\
\hline 9 & $\mathrm{Ar}^{+}+$wall $\rightarrow \operatorname{Ar}(\mathrm{GL})$ & Recombination on the wall, see text \\
\hline
\end{tabular}


consequently the electronic density calculated by the CGM are very sensitive with the values of the ionization cross sections, hence of the rate coefficients introduced in the collisional energy losses calculation.

In case of plasma reactors working in ICP mode, most of the created ions are expected to recombine on the metallic wall, and the ionization percentage does not usually exceed $1 \%$. In those conditions, in view of the also low percentage of the excited states population, all the energy is practically lost by electron collisions with neutral ground level particles $\mathrm{Ar}_{\mathrm{GL}}-e^{-}$in elastic, excitation, and ionization collisions. Populations of the ionized species are orders of magnitude smaller (cf. Figure 4 of Section 5).

A somehow different situation is encountered in HT, where ionization percentage in the bulk of the plasma stays typically lower than $10 \%$, as suggested by current measurements of optical emission spectroscopy (OES); see for example, [1]. However, this percentage may exceed $90 \%$ in the core region of the plasma (see Figure 1), while staying substantially lower in the external plasma region, the mantle region. Near the wall, where the sheath is formed, the percentage can even fall to less than $1 \%$. Consequently, in this external region, the plasma conditions can be considered as rather similar to those typically observed in plasma reactors. Even if the recombination on the wall (e.g., made of Pyrex) may be lower for the thruster, it is still very important for the overall ionization equilibrium, while the radiative recombination remains negligible. We also take into account the eventuality of having a low percentage (e.g., less than $10 \%$ ) of the core ions being lost by leaving the core towards the mantle region, where they also recombine on the wall. In a simplified scheme, choosing the cross section area of the core $A_{C}$ to be about $10 \%$ of the total thruster section area, that is, $A_{C} \sim 0.10 A_{T}$, we are left with $90 \%$ belonging to the mantle area. This scheme follows recently obtained OES results [1], locating an essential concentration of ions in the core, with a very low percentage of neutrals, while in the mantle the very low ionization percentage is taken approximately as constant. In such a scheme, for a typical thruster radius of $R_{T}=1 \mathrm{~cm}$, we obtain $R_{C} / R_{T}=$ $\left(A_{C} / A_{T}\right)^{1 / 2}=(0.1)^{1 / 2}$, say 0.316 , with $R_{C}=0.316 \mathrm{~cm}$ as shown in scale in Figure 1.

\section{Collisional Energy Losses from the Neutral and the Ionized Components of the Plasma}

The general properties of the electron collisional energy loss parameter $\varepsilon_{C}$ are very important in determining where the absorbed energy is spent. The collisional energy loss of $\mathrm{Ar}$ and this of $\mathrm{Ar}^{+}$that are of interest here are obtained on the basis of extensive calculations and evaluations of atomic data [2]. Typical $\varepsilon_{C}$ results for two argon species and also for $\mathrm{N}_{2}$ plasmas for comparison are given by the curves shown in Figure 2. In this figure, results existing in the literature are also presented. The observed differences in the neutral $\mathrm{Ar}$ and $\mathrm{N}_{2}$ cases are due to the use of various databases and/or to consideration of a more or less restricted set of collisional processes. This choice may result to a

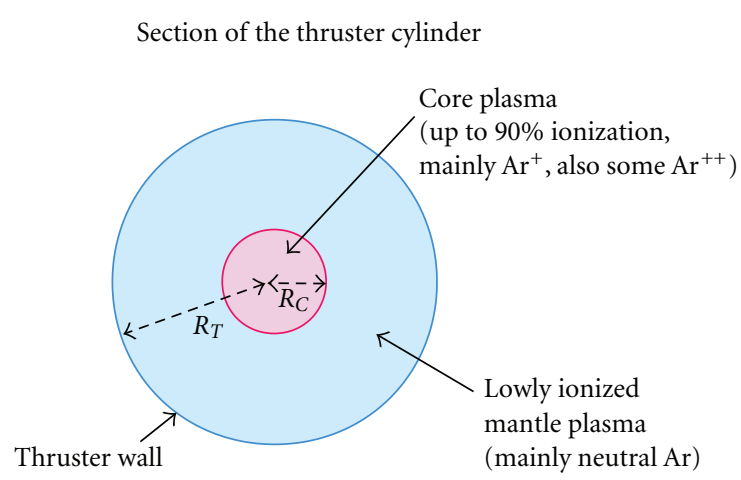

FIGURE 1: Vertical section of the thruster source cylinder.

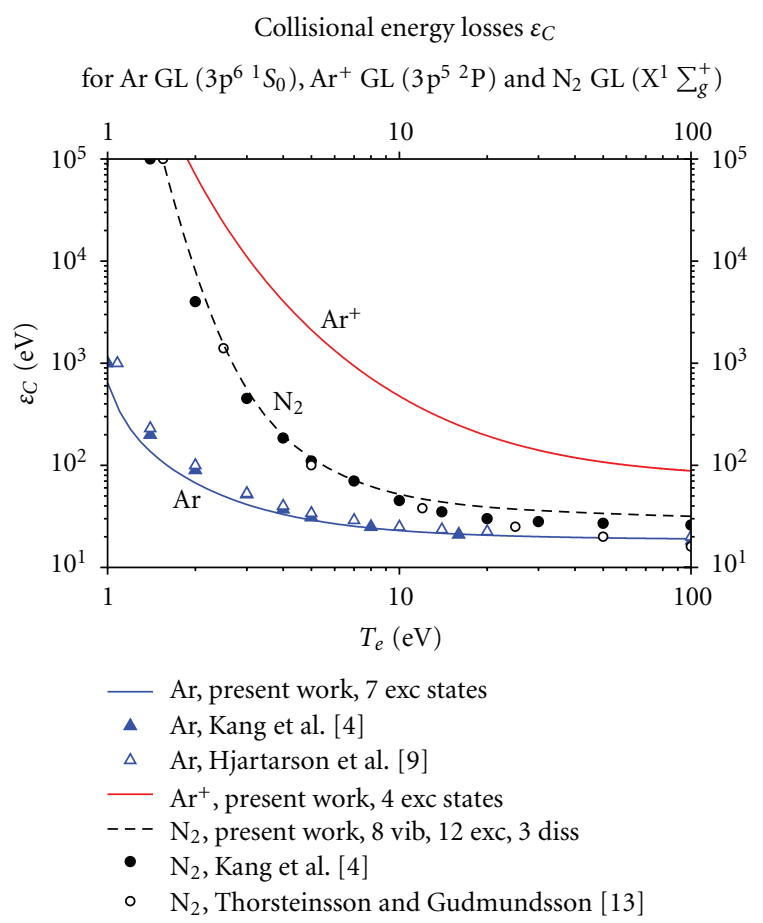

Figure 2: Collisional energy losses for $\mathrm{Ar}, \mathrm{Ar}^{+}$, and $\mathrm{N}_{2}$.

considerable lowering of the $\varepsilon_{C}$ values. The most important feature illustrated in Figure 2 is the presence of much higher $\mathcal{E}_{C}$ values in the $\mathrm{N}_{2}$ case, in comparison to those obtained for Ar plasmas. This well-known feature is essential due to the presence of vibrational extra states for the former, the latter having no significant molecular components. Our results for $\mathrm{Ar}$ (blue line) and $\mathrm{Ar}^{+}$(red line) species are plotted in Figure 2 by continuous lines, as a function of the electronic temperature $T_{e}$. It can be seen that much more energy is lost in one electron collision for excitation and ionization of $\mathrm{Ar}^{+}$ions, than in the case of $\mathrm{Ar}$ atoms. For Ar atoms, results obtained by Kang et al. [4] and Hjartarson et al. [9] are also given in Figure 2, by full and empty triangles, correspondingly. These are very near to our values for high $T_{e}$ but consistently higher than ours for lower ones. This discrepancy is attributed to different rate coefficients which we used in our study, taking into account the exact cross 
TABLe 6: Approximate collisional energy losses in the mantle plasma region.

\begin{tabular}{lcccc}
\hline Species & $T_{e}$ & $\varepsilon_{C}$ for only one component & Presence in $n_{\text {TOT }}$ percentage & Effective energy losses \\
\hline Ar I $(\mathrm{Ar})$ & 4 & 32 & $99 \%$ & 31.7 from Ar I \\
Ar II $\left(\mathrm{Ar}^{+}\right)$ & 4 & 3000 & $1 \%$ & 40 from Ar II \\
\hline Total $\mathrm{Ar}(\mathrm{I}+\mathrm{II})$ & & & $100 \%$ & 71.7 total $\varepsilon_{C}$ \\
\hline
\end{tabular}

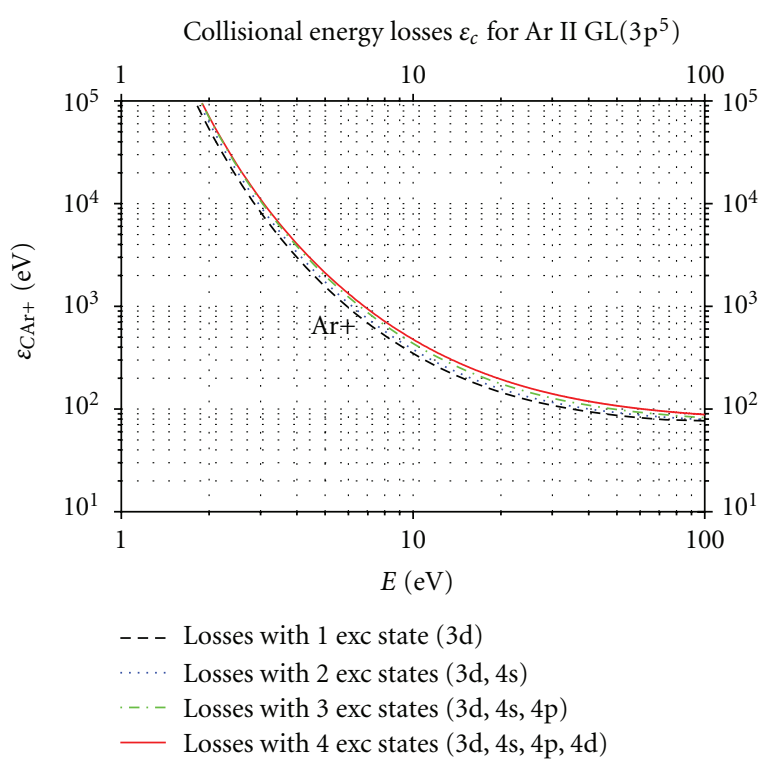

FIgURE 3: Various collisional energy loss results for $\mathrm{Ar}^{+}$.

sections near the threshold. Electron collisional losses to Ar species are also compared with those obtained in the case of a molecular gas, here $\mathrm{N}_{2}$, with the help of Figure 2. Nitrogen was often used in plasma reactors. It is also considered as a possible component when seeking "green" propellant feeding in space propulsion devices. The results of our collisional energy losses calculations for $\mathrm{N}_{2}$ are shown in Figure 2 by a broken line, while $\mathrm{N}_{2}$ results from the aforementioned work [4] are shown by full circles and those from Thorsteinsson and Gudmundsson [13] by empty ones. As expected, much lower values were obtained by the latter authors for high $T_{e}$ because the collisional $\mathrm{N}_{2}$ dissociation leading to $\mathrm{N}$ atoms, which becomes very important in these temperatures, has not been taken into account. Values of $\varepsilon_{C}$ given in [4] are lower than ours for higher $T_{e}$. We believe that this is due to the inclusion of a sole dissociation process instead of three, which are included in our case. The reason of the discrepancy in the $2 \mathrm{eV}$ and lower region is not clear to us. Besides, we verify here that $\varepsilon_{C}$ for molecular gases is typically higher than $\varepsilon_{C}$ for atomic ones, due to the inclusion of the molecular excitations and dissociation. However, $\varepsilon_{C}$ for ionic species is even higher, due to the substantially higher ionization and excitation energies of the ion involved.

Collisional energy loss results for ionized $\mathrm{Ar}^{+}$when one, two, three, and four excited states are taken into consideration are represented and described in Figure 3. From inspection of this figure, we conclude that inclusion in the $\varepsilon_{C}$ calculations of the main (lowly) excited states of

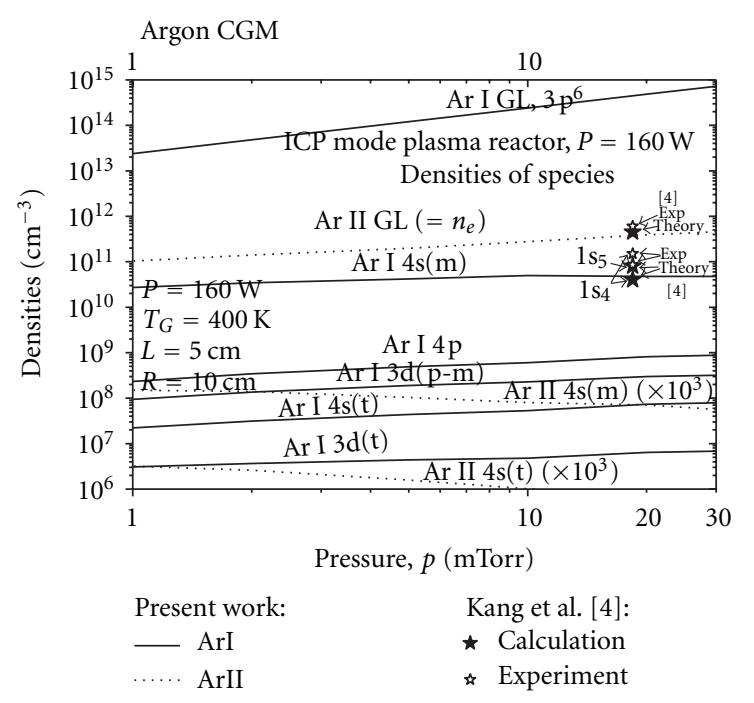

FIGURE 4: Plasma reactor calculated densities of Ar I GL, Ar I excited species, Ar II GL, and Ar II 4s(m), 4s(t) species. Pressure varies from $1 \mathrm{~m}$ Torr to $30 \mathrm{mTorr} ;(\mathrm{m})=$ metastable, $(\mathrm{t})=$ transitory, $(\mathrm{p}-\mathrm{m})=$ pseudometastable.

$\mathrm{Ar}^{+}$is important. As previously noted, $\varepsilon_{C}$ values for $\mathrm{Ar}^{+}$are in any case much higher than those for neutral Ar and for $\mathrm{N}_{2}$ for the same $T_{e}$, due to the much higher ionization and excitation energies of $\mathrm{Ar}^{+}$in comparison to those of Ar.

As an example of the Ar plasma collision energy losses mechanisms in a thruster, let us suppose that the core plasma electronic temperature is, for example, $T_{e}=6 \mathrm{eV}$, while the mantle one is about $T_{e}=4 \mathrm{eV}$. In such a case, where the pressure is supposed to be about $5 \mathrm{mTorr}$ for a power of $50 \mathrm{~W}$, we obtain in the mantle a global $\varepsilon_{C}$ of $71.7 \mathrm{eV}$, with $31.7 \mathrm{eV}$ spent to the $\mathrm{Ar}$ neutrals and $40 \mathrm{eV}$ spent to $\mathrm{Ar}^{+}$ions, as shown in the Table 6 , where all $T_{e}$ and $\varepsilon_{C}$ values are given in $\mathrm{eV} . T_{e}$ values considered in this table correspond to separate CGM solutions for each input set. Also, collisional energy losses from $\mathrm{Ar}$ and $\mathrm{Ar}^{+}$have been restricted to those in the mantle region $\left(T_{e}=4 \mathrm{eV}\right)$. Note that in the Table 6, we used approximately $n_{\mathrm{TOT}}=n_{\mathrm{Ar}}+n_{\mathrm{Ar}}$ although a small amount of $\mathrm{Ar}^{++}$ions is also present.

With increasing absorbed power, the total collisional energy loss, including the much higher values of the ion energy losses part (cf. Figure 2 and Table 6 ) may easily reach substantially higher values than the $71.7 \mathrm{eV}$ of the Table 6 . According to [14] and references therein, experimental data and theoretical analyses show that ionization cost values from $70 \mathrm{eV}$ and up are realistic in helicon thrusters. It is reported in [14] that these may even reach values exceeding $200 \mathrm{eV}$. 


\section{Ar CGM Results for Plasma Reactor Modeling and Comparisons with Measurements}

Aiming a first type of applications, we adapted our CGM in order to model and to characterize typical argon plasma reactors. In doing so, we considered three typical ICP mode plasma reactors with different absorbed powers and form factors. Results coming from our Ar CGM calculations are presented and commented hereafter. These are compared successively with existing related experimental and GM results for typical ICP Ar plasma reactors, first with those given in [4] (Part A) and then with those given in [9] (Parts $\mathrm{B}$ and $\mathrm{C}$ ). Note that both [4] and [9] are studying principally Ar mixtures reactors with $\mathrm{N}_{2}$ and $\mathrm{H}_{2}$, correspondingly. Experimental results of [4] have been measured using resonance absorption spectroscopy for metastables densities and Langmuir probes for electron densities and temperature. Langmuir probes measurements and OES techniques have been used in available Ar plasma experiments $[15,16]$ reported in [9].

(A) ICP Reactor of $P=160 \mathrm{~W}, \mathrm{~L}=5 \mathrm{~cm}$ Length, and $R=$ $10 \mathrm{~cm}$ Radius, See [4]. Our model is applied in this case to an ICP discharge with absorbed power $P=160 \mathrm{~W}$. A length of $L=5 \mathrm{~cm}$ and a radius of $R=10 \mathrm{~cm}$ have been used as typical dimensions.

Data presented for this application suppose a neutral feeding gas temperature of $T_{\mathrm{GAS}}=400 \mathrm{~K}$, while the reactor is fed with $50 \mathrm{sccm}$ of Ar. In the collision energy loss calculations of our model, we included seven averaged excited levels, namely, $4 \mathrm{~s}(\mathrm{~m}), 4 \mathrm{~s}(\mathrm{t}), 4 \mathrm{p}, 3 \mathrm{~d}(\mathrm{p}-\mathrm{m}), 3 \mathrm{~d}(\mathrm{t}), 5 \mathrm{~s}(\mathrm{p}-$ $\mathrm{m})$, and $5 \mathrm{~s}(\mathrm{t})$. Populations of only the first five of them were calculated and appear explicitly in the particle balance equations. Ar II excited species taken into consideration are those appearing in Figure 3, namely, the 4s, 3d, 4p, and 4d averaged configurations, but only the $4 \mathrm{~s}(\mathrm{~m})$ and $4 \mathrm{~s}(\mathrm{t})$ species populations are calculated. The obtained variations of the Ar I GL and of the Ar II GL densities and of some of their excited states are illustrated in Figure 4. For a substantial variation of the total pressure from $1 \mathrm{mTorr}$ to $30 \mathrm{mTorr}$, we obtained a continuous increase of the ground level neutrals, approximately from $2.5 \cdot 10^{13} \mathrm{~cm}^{-3}$ up to $70 \cdot 10^{13} \mathrm{~cm}^{-3}$ for Ar I. Increase of Ar II population and consequently of $n_{e}$ was clearly lower, from $1 \cdot 10^{11} \mathrm{~cm}^{-3}$ to $4 \cdot 10^{11} \mathrm{~cm}^{-3}$ approximately.

When the pressure increases, the neutral species densities also increase, while the $T_{e}$ diminishes as we will see later (cf. Figure 5). The corresponding GL ion density is slowly increasing, but the ionization percentage is regularly decreasing. However, because of this decrease, both Ar II excited $4 \mathrm{~s}$ states densities slightly decrease, on the contrary of those of Ar I. Here we applied the quasineutrality principle, then the $n_{e}$ is practically equal to the argon ion density. Also, for the total density of particles, we used the perfect gas law. In Figure 4, theoretical and experimental results for pure Ar plasma from Kang et al. [4] for a pressure of $20 \mathrm{mTorr}$ are also included, shown with full and empty stars correspondingly. Although lower than the experimental ones, our theoretical

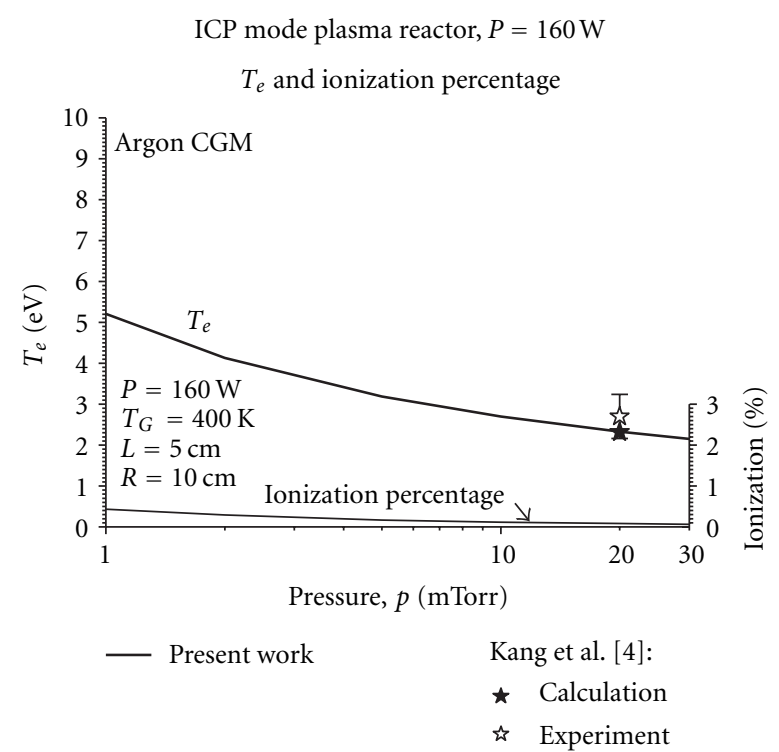

Figure 5: Calculated $T_{e}$ and ionization percentage in the plasma reactor.

results for the $n_{e}$ density are practically the same with the theoretical values obtained by Kang et al. [4]. Moreover, these authors have calculated/measured results for all $4 \mathrm{~s}$ states separately, also shown in Figure 4. Our results for an averaged $4 \mathrm{~s}(\mathrm{~m})$ level is conform to the averaged values of those results, although the radiative loss rates attributed are inconsistent. Note that when optical absorption is taken into consideration, the transitory $4 \mathrm{~s}(\mathrm{t})$ density is the one increasing dramatically (cf. next figures). However, our $4 \mathrm{~s}(\mathrm{t})$ density values were initially, as expected, much lower than those of the $4 \mathrm{~s}(\mathrm{~m})$ and so affect less the much higher $4 \mathrm{~s}(\mathrm{~m})$ values.

Concomitant variation of the $T_{e}$ corresponding to the variation of pressure shown in the pressure region of Figure 4 ( 1 mTorr to $30 \mathrm{mTorr}$ ) as obtained by our CGM is represented in Figure 5. We observe that $T_{e}$ is reduced to about its half in the $1 \mathrm{~m}$ Torr to $30 \mathrm{~m}$ Torr region. For a pressure of 20 mTorr, our results are very near to the theoretical values of Kang et al. [4] also presented in the figure, staying within the experimental data error bar. The calculated ionization percentage is given in the right side of the Figure 5. It stays relatively low, diminishing with the $T_{e}$ from less than $0.5 \%$ down to $0.1 \%$, for a $T_{e}$ reduced from 5 to $2 \mathrm{eV}$.

Our model stays valid in a large pressure region. Results for $1 \mathrm{~m}$ Torr to $500 \mathrm{mTorr}$ are shown in Figure 6. Those obtained with the intermediate pressure formulas (3) are here given by dashed curves, while those obtained with the extended application formulas (4), spanning a larger pressure region, are given by continuous ones. It can be easily seen that the two formulas give practically the same results for pressures up to 10 mTorr.

Figure 7 shows theoretical values obtained in [4] incorporating an optical escape factor and the corresponding experimental ones obtained by the same authors, together with our theoretical results. Although our $n_{e}$ values compare well with the experimental ones, those of $4 \mathrm{~s}(\mathrm{~m})$ presented 


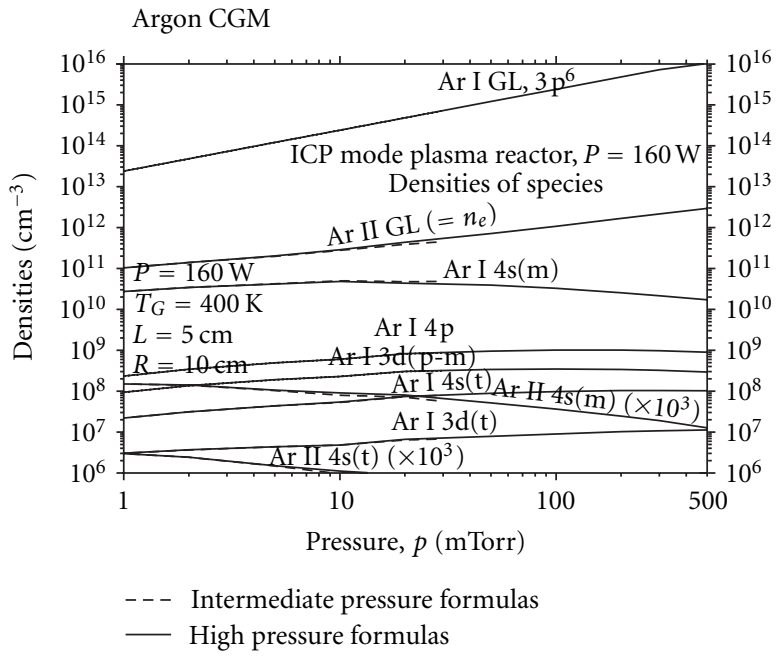

FIgURE 6: As in Figure 4 but for pressures up to 500 mTorr.

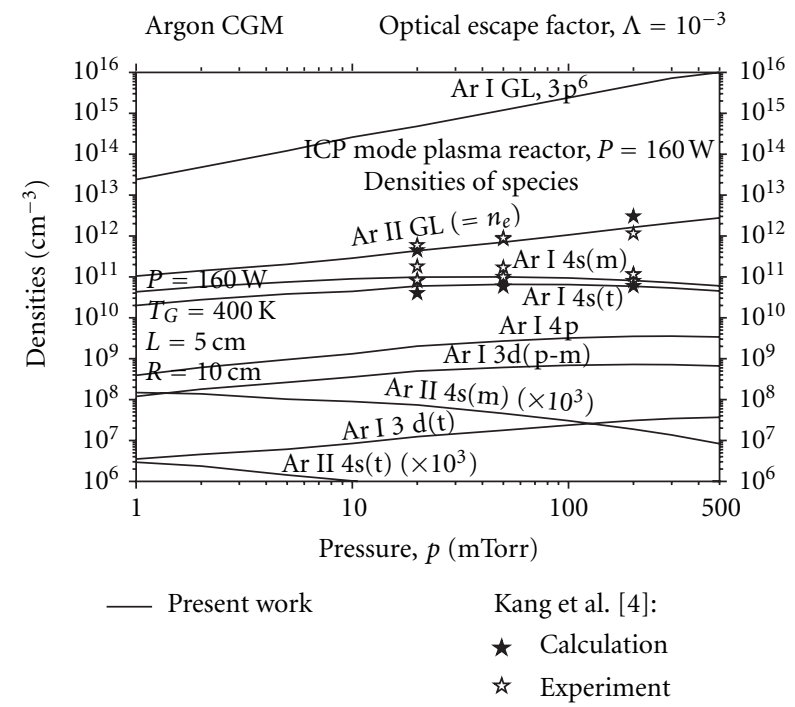

Figure 7: As in Figure 6 but including an optical escape factor for the $4 \mathrm{~s}(\mathrm{t})$ Ar I level. Theoretical and experimental results from [4] are also included.

in Figure 6 were much lower. This is due to the fact that we did not initially include any line reabsorption in our model, the plasma being supposed to be optically thin. By including such a factor, we see that although $\operatorname{Ar}_{\mathrm{GL}}$ diminishes very slightly, $n_{4 s}(\mathrm{~m})$ increases considerably; the transitory state density $n_{4 s(t)}$ increases drastically. Inclusion of a reabsorption factor of $\Lambda=10^{-3}$ leads to results shown in Figure 7. These are even nearer to the experiment than the theoretical results reported in [4]. Similar changes for the Ar II levels are expected when an optical escape factor is included for Ar II levels.

Figure 8 shows calculated $T_{e}$ values for various pressures without (continuous line) and with (broken line) reabsorption. There is not a notable difference between the two curves, therefore the reabsorption, if any, plays in the present conditions a minor role in the plasma heating and ionization

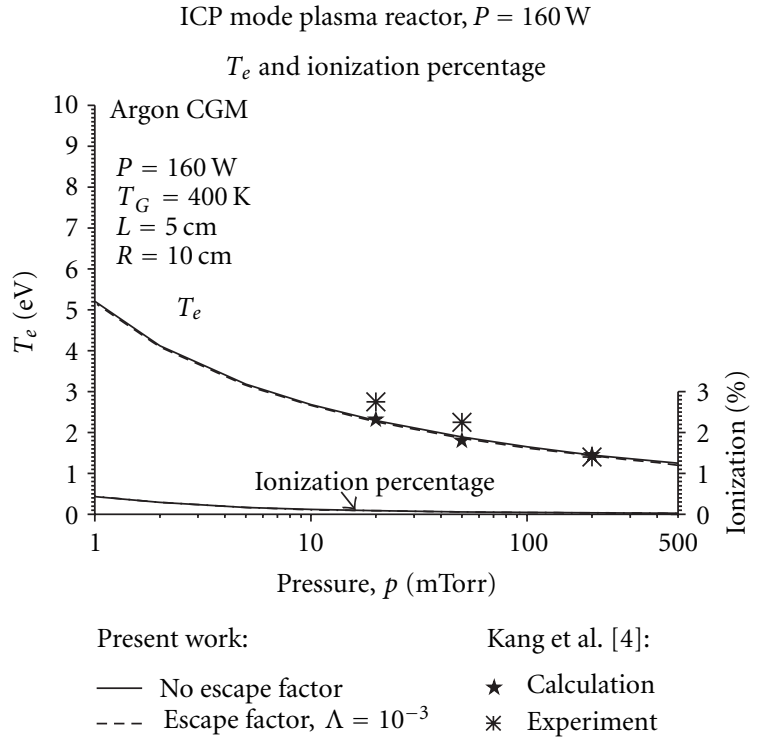

Figure 8: Calculated $T_{e}$ and ionization percentage in the plasma reactor for $1 \mathrm{mTorr}<p<500 \mathrm{mTorr}$. Ionization percentage is to be read in the right side scale.

percentage. Our results are in satisfactory agreement with those from [4]. Corresponding ionization percentage results are also shown.

(B) ICP Plasma Reactor of $P=600 \mathrm{~W}$, Length $L=7.62 \mathrm{~cm}$, and Radius $R=15.24 \mathrm{~cm}$. Results of our model are given here for an ICP discharge with absorbed power of $P=600 \mathrm{~W}$ and dimensions of $L=7.62 \mathrm{~cm}$ length and of $R=15.25 \mathrm{~cm}$ radius. These conditions have been selected in accordance with $[9,15]$.

We assume the gas temperature to be $T_{\mathrm{GAS}}=500 \mathrm{~K}$ and the flux to be $Q_{\mathrm{Ar}}=50 \mathrm{sccm}$. Densities for the Ar I and Ar II species were calculated as in Part (A), but here, only the wider application domain formulas (4), valid also for high pressures, have been used throughout and without including any absorption factor. Variations of the Ar I GL and of some of the Ar I excited states are presented in Figure 9, in the pressure range from 1 to 100 mTorr. This figure shows also the electronic density results from our model, which is compared with the GM results of [9] and the experimental results of Gudmundsson [15] as quoted in [9]. A very good agreement is obtained for electronic density with results from these two different sources. However, the corresponding values for the electron temperature shown in Figure 10 are noticeably different and even lower than the experimental ones. Ionization percentage from our model is also given in Figure 10.

(C) ICP Plasma Discharge of $P=120 \mathrm{~W}$, Length $L=7.50 \mathrm{~cm}$, and Radius $R=8.00 \mathrm{~cm}$. Here, we apply our model to another ICP discharge with absorbed power of $P=120 \mathrm{~W}$, with a length of $L=7.50 \mathrm{~cm}$ and a radius of $R=8.00 \mathrm{~cm}$; conditions taken to be conformal with those used in [9]. 


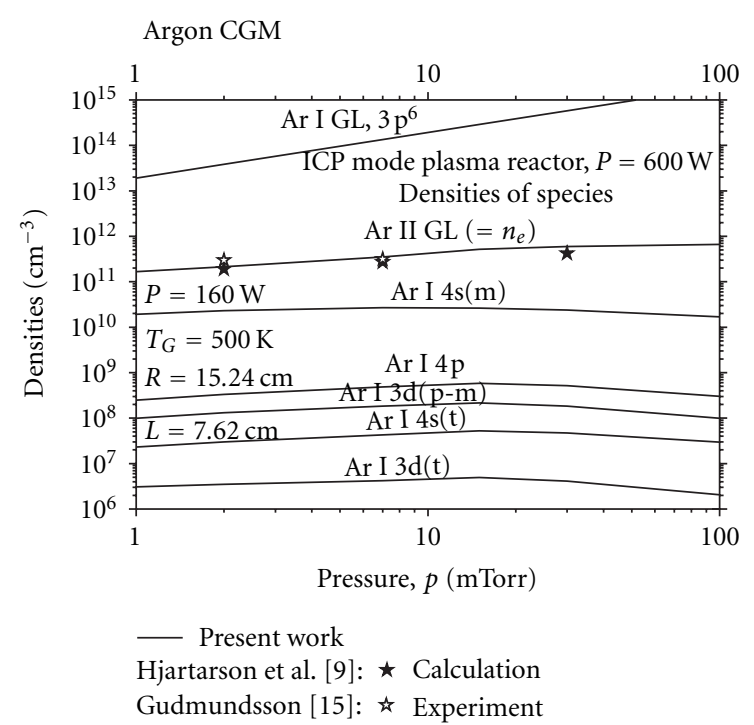

Figure 9: Calculated densities of species in the plasma reactor for 1 mTorr $<p<100$ mTorr and comparison with values of Hjartarson et al. [9] and with those of Gudmundsson (quoted in [9]).

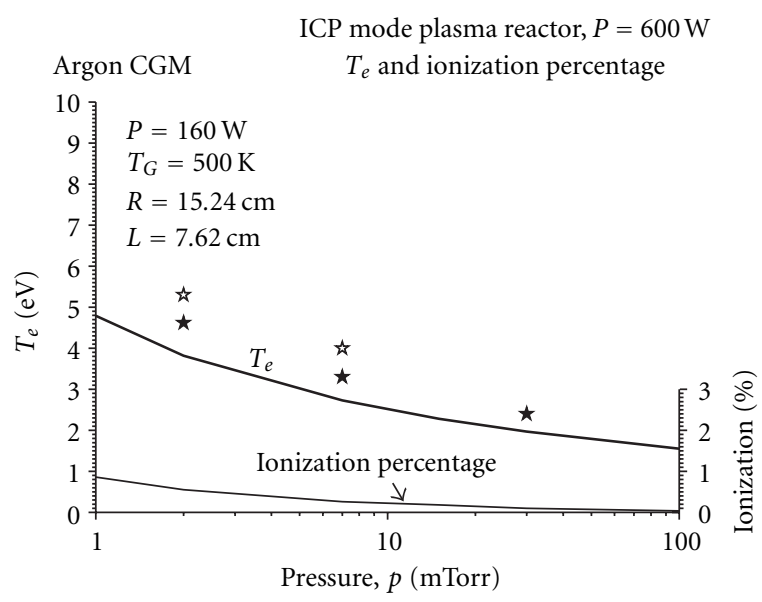

Present work
Hjartarson et al. [9]: ^ Calculation
Gudmundsson [15]: $\star$ Experiment

FIgURE 10: Calculated $T_{e}$ and ionization percentage in the plasma reactor for 1 mTorr $<p<100$ mTorr and comparison with values of Hjartarson et al. [9] and with those of Gudmundsson (quoted in [9]).

We assume the gas temperature to be $T_{\mathrm{GAS}}=400 \mathrm{~K}$ and the flux to be $Q_{\mathrm{Ar}}=35 \mathrm{sccm}$ and calculate Ar I and II densities as in Part (B). Variations of the Ar I GL densities and of some of its excited states for the present conditions are shown in Figure 11, for a pressure range from 1 to 100 mTorr. Our model results for electronic density are also shown, together with GM results of [9] and experimental results of Kimura and Kasugai [16], as quoted in [9]. A very good agreement is obtained for electronic density and particularly with experimental results. The corresponding results for the

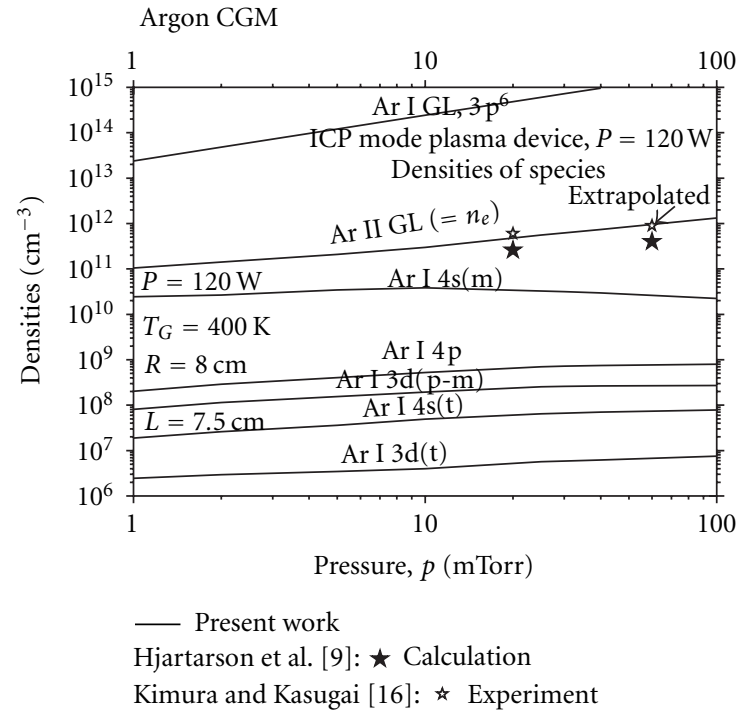

FIGURE 11: Calculated densities of species in the plasma reactor for 1 mTorr $<p<100$ mTorr. Comparison with values of Hjartarson et al. [9] and Kimura and Kasugai [16].

electron temperature and the ionization percentage are given in Figure 12. Two sets of experimental results are represented with dashed lines joining stars; one corresponding to the electron distribution bulk and the second to higher energy electrons. The dashed lines are only meant to ease the eye. Theoretical GM results of [9] are also shown in Figure 12. We see that our $T_{e}$ results are a little lower than those of [9], but they are still situated between the two sets of experimental $T_{e}$ results from Kimura and Kasugai.

\section{Study of Plasma Thrusters Using an Ar CGM}

The previously described CGM has been adapted and used also in a separate study of the cooler (mantle) and hotter (core) regions of a plasma thruster. In doing so, in view of the concomitant optical diagnostics requirements, we kept the aforementioned five collective excited states of the neutral Ar in the particle balance equations together with two collective excited states of Ar II. Note that real levels have been split into those showing a transitory and those showing a metastable character. Nontransitory $3 \mathrm{~d}$ levels have been characterized as pseudometastable because even being situated in the low-energy region of the energy level diagram near the $4 \mathrm{~s}$ levels, they could not relax to them because $\mathrm{d}-\mathrm{s}$ transitions are not allowed and their transitions to the GL are also forbidden. Within each of the considered configurations, levels of each category (transitory-metastable) were averaged and so constituted one global level. The separate averaging of levels of the same character, not only gives sufficient information about their collective population, but also takes account of the presence of metastable and pseudometastable levels in the Ar species, illustrating their different role on the overall argon plasma equilibrium. This is necessary in order to obtain realistic populations and a good excitationde-excitation balance, hence to evaluate the correct plasma 


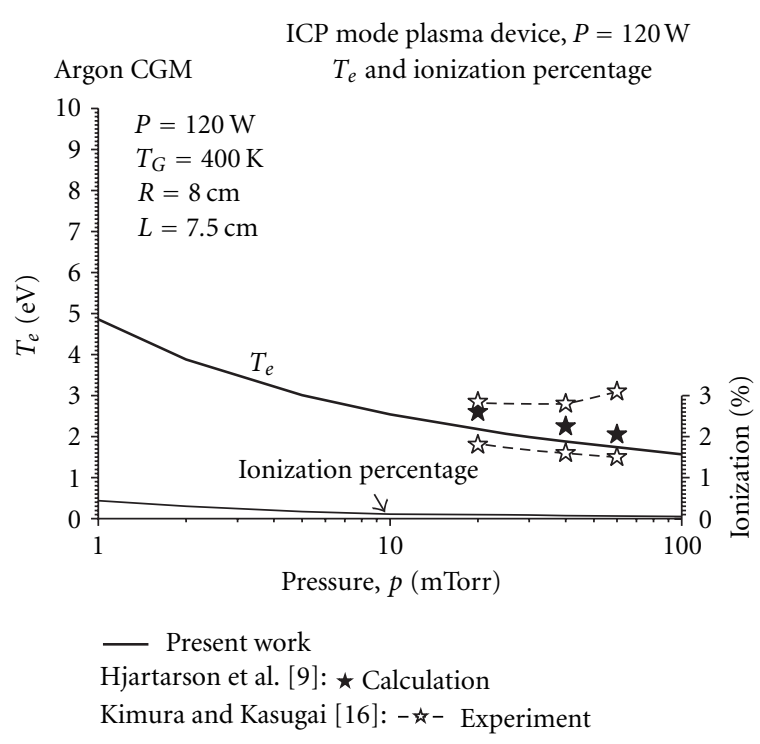

FIgURE 12: Calculated $T_{e}$ and ionization percentage for $1 \mathrm{mTorr}<$ $p<100$ mTorr compared with values of Hjartarson et al. [9] and of Kimura and Kasugai [16].

parameters. In selecting the overall dimensions of the plasma thruster, we have chosen typical values of length $(L=$ $13.0 \mathrm{~cm})$ and of radius $(R=1.0 \mathrm{~cm})$ that are included among those often encountered in applications. However, our studies suggest an easy application of the model using other form factors (see Section 7) taking advantage of the model versatility and in view of a better description of the thruster plasma. Here, we address specifically modeling of a low-power helicon thruster. We apply separately the model to its outer, cooler region and to its inner, hotter one. Results are described and discussed separately in the following parts (A) and (B) of the Section.

(A) Mantle Plasma Region of a Helicon Thruster or Lowly Ionized Regions in Other EP. Although this part addresses specifically the mantle region of a low power helicon plasma thruster, a situation somehow similar is encountered in other low power thrusters. Main results of our CGM model for the mantle plasma are illustrated in Figures 13 and 14 . Variation of the densities of the neutral Ar GL and of its excited states and also of those of $\mathrm{Ar}^{+}$ion are presented in Figure 13 as a function of the pressure, when the absorbed power is $50 \mathrm{~W}$. Furthermore, the corresponding $T_{e}$ and ionization percentage are given in Figure 14. Collisional energy losses from $\mathrm{Ar}^{+}$ion have been included throughout, even in the mantle region calculations addressed in this part, although the expected ions percentage in this region is lower than this of the core. Detailed consideration of the ion species constitutes an improvement even on the CGM form that is used usually in PR modeling, where the model is meant to describe mostly lowly ionized plasmas. Neglecting of the $\mathrm{Ar}^{+}$losses becomes unsatisfactory as ionization percentage $\xi$ increases. However, it remains always sufficient for description of the lowly ionized plasmas currently present

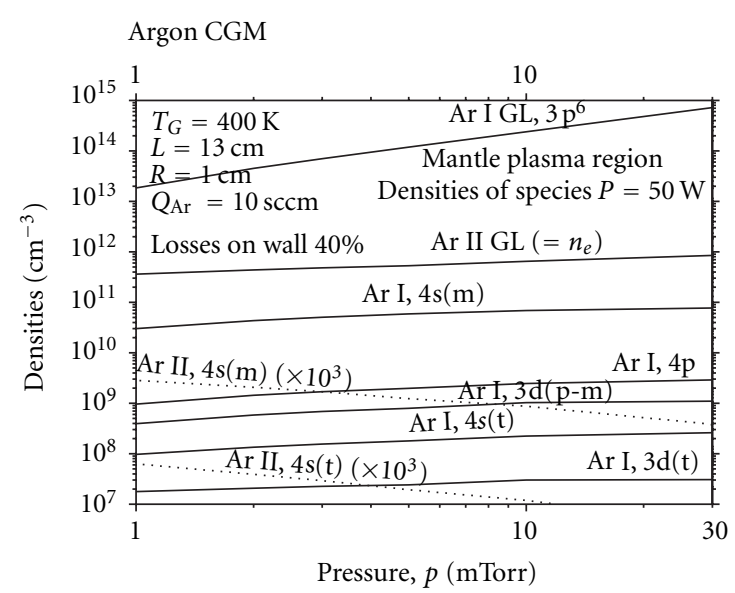

FIGURE 13: Calculated densities of $\mathrm{Ar}_{\mathrm{GL}}$, Ar excited species, and $\mathrm{Ar}^{+}$ in the mantle plasma region; $(\mathrm{m})=$ metastable, $(\mathrm{t})=$ transitory, $(\mathrm{p}$ $\mathrm{m})=$ pseudometastable.

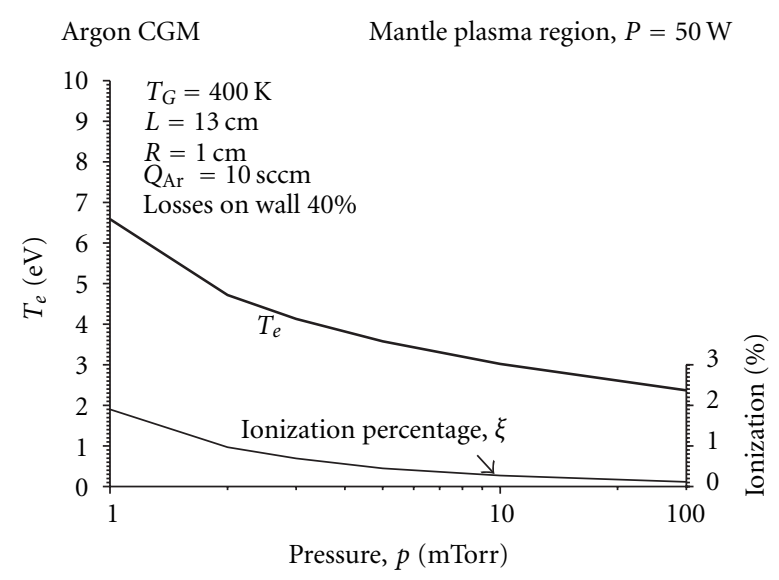

FIgURE 14: Calculated $T_{e}$ and ionization percentage in the mantle plasma region.

in PR when the pressure is not very small and the $T_{e}$ not very high.

In Figure 13, we see that the population of Ar II $4 \mathrm{~s}(\mathrm{~m})$ species is exactly four orders of magnitude smaller than this of $\operatorname{ArI~} 4 \mathrm{~s}(\mathrm{~m})$ for a low pressure of $1 \mathrm{mTorr}$ which corresponds to a relatively high $T_{e}$ of $6.5 \mathrm{eV}$ and to an ionization percentage of about $2 \%$ as we infer from Figure 14 . Although considerably smaller than those of Ar II GL and Ar I $4 \mathrm{~s}(\mathrm{~m})$, and also lower than those of Ar I $4 \mathrm{p}$ and $3 \mathrm{~d}$ even in this high $T_{e}$ region, separate calculation of Ar II excited species population allows for a convenient OES [1, 17]. OES has been also currently used in the case of the plasma reactors, even if the corresponding $T_{e}$ and $\xi$ are often even lower. (See Section 7).

For an absorbed power of $50 \mathrm{~W}$, which is quite lower than this of the previous PR examples, all densities of neutral species increase together with the pressure, when the latter increases from $1 \mathrm{~m}$ Torr to $30 \mathrm{mTorr}$. This is illustrated in Figure 13, where it can be seen that the neutral $3 \mathrm{p}^{6}$ density $\left(=n_{\mathrm{GL}}\right)$ increases about forty times with a pressure increasing 
from 1 to $30 \mathrm{~m}$ Torr. In a concomitant variation, $n_{e}$ increases roughly two times, going from about $3.5 \cdot 10^{11} \mathrm{~cm}^{-3}$ up to $8.5 \cdot 10^{11} \mathrm{~cm}^{-3}$, as is also shown in Figure 13 . Because here we describe only the stationary state case, once the chosen pressure is achieved, the number of particles pumped in equals to the number of those pumped out, and so the pressure is stabilized. The total flow of gas exhausted from the thruster depends on the injected flow, and the stabilized pressure is related to the plasma volume and to the total density of species. The latter depends on the pressure and gas temperature, which is related to the ionization percentage when considering $T_{\text {ions }}$.

To the aforementioned increases of the $n_{\mathrm{GL}}$ and of the $n_{e}$, corresponds a depletion of $T_{e}$ to about one third, while the ionization percentage $n_{e} / n_{\text {TOT }}$ falls more than one order of magnitude. This can be verified by inspection of Figure 14 .

Inclusion of $\mathrm{Ar}^{+}$species in the model may also influence the overall temperature and ionization, besides being important for optical diagnostics. Even in the mantle region, where the ionization percentage is not exceeding $2 \%$, when the $\varepsilon_{C}$ values of $\mathrm{Ar}^{+}$plotted in Figure 3 are taken into account, we observe a considerable influence on the $n_{e}$ results. This can be seen in the following Figure 15, which is presenting results similar to those of Figure 14, but including also the values obtained when $\mathrm{Ar}^{+}$energy losses are neglected. The latter values are shown by broken lines, while our results including $\varepsilon_{C}$ of $\mathrm{Ar}^{+}$are shown by continuous red lines. Note that for a pressure of about $30 \mathrm{~m}$ Torr with very low $\xi$ and a $T_{e}$ less than $3 \mathrm{eV}$, inclusion of the $\mathrm{Ar}^{+}$species has no interest for modeling.

B. The Core Plasma Region of a Helicon Plasma Thruster. For the core plasma region of a helicon thruster, our model also results to the evaluation of the species densities, of the plasma $n_{e}$, and $T_{e}$ and of the ionization percentage. These are shown schematically in Figures 16 to 19 . For all calculations concerning HT, we use the simple approximation proposed by Lieberman and Lichtenberg [7] based to the collisionless Landau Dumping mechanism, which is expected to become predominant in Ar plasmas at pressures lower than 10 mTorr. This approximation leads to a reduction of the $\varepsilon_{C}$ term to a steady-state value of twice the ionization energy. We investigated the variation of the basic plasma parameters as a function of the pressure. Figure 16 shows the obtained variation of the densities of species, while Figure 17 shows our results for the variation of the $T_{e}$ and of the corresponding ionization percentage. In both Figures 16 and 17, the pressure varies from 2 to $10 \mathrm{~m}$ Torr. The absorbed power was fixed at $100 \mathrm{~W}$, and the core radius is $R_{C}=0.3 \mathrm{~cm}$.

We see in Figure 16 that the GL density increases with the pressure as well as the densities of the excited states. The density of the $4 \mathrm{~s}$ metastable state varies from $1 \cdot 10^{10}$ to $3 \cdot 10^{10} \mathrm{~cm}^{-3}$ when the pressure increases from 2 to $10 \mathrm{mTorr}$, while it was about three times higher in the mantle region. In the opposite, the density of the excited states $4 \mathrm{p}, 3 \mathrm{~d}(\mathrm{p}-\mathrm{m})$, and $4 \mathrm{~s}(\mathrm{t})$ are about four times higher in the core region than in the mantle, and the density of the $3 \mathrm{~d}(\mathrm{t})$ is about ten times higher. This is conformal to the experimental and theoretical

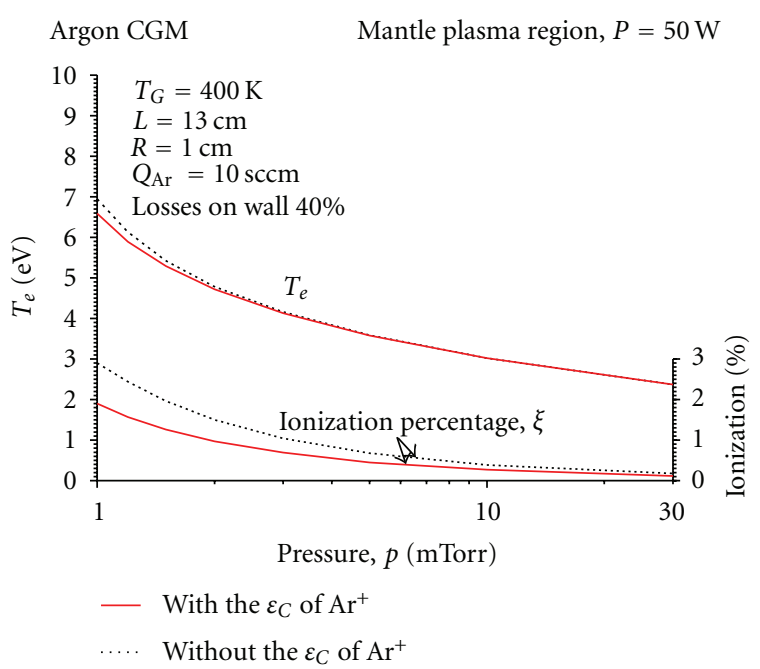

FIGURE 15: Calculated $T_{e}$ and ionization percentage in the mantle plasma region.

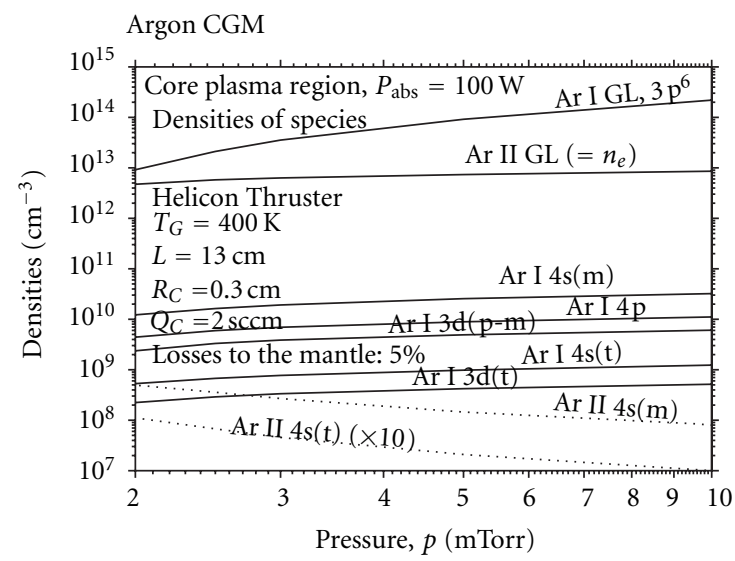

Figure 16: Calculated densities of $\mathrm{Ar}_{\mathrm{GL}}$, $\mathrm{Ar}$ excited species, and $\mathrm{Ar}^{+}$ versus pressure in the core plasma region of a helicon thruster.

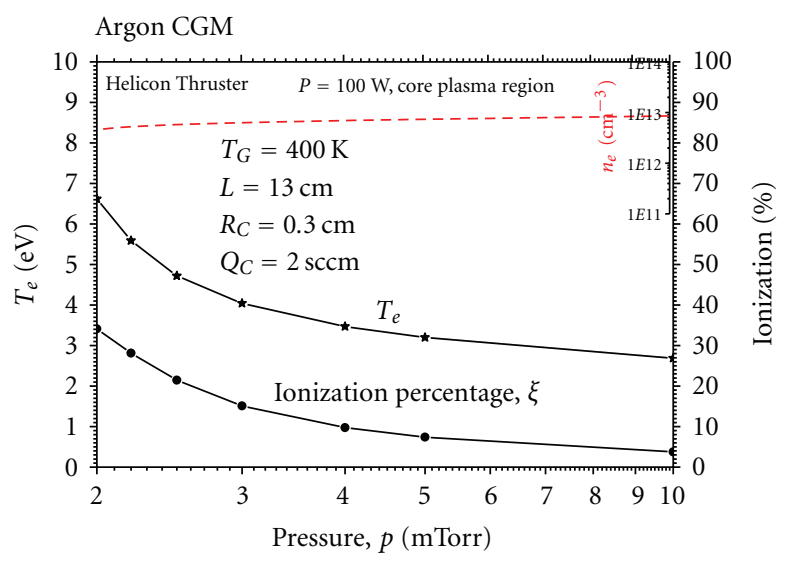

Figure 17: Calculated $n_{e}, T_{e}$, and ionization percentage versus pressure in the core plasma region of a helicon thruster. 


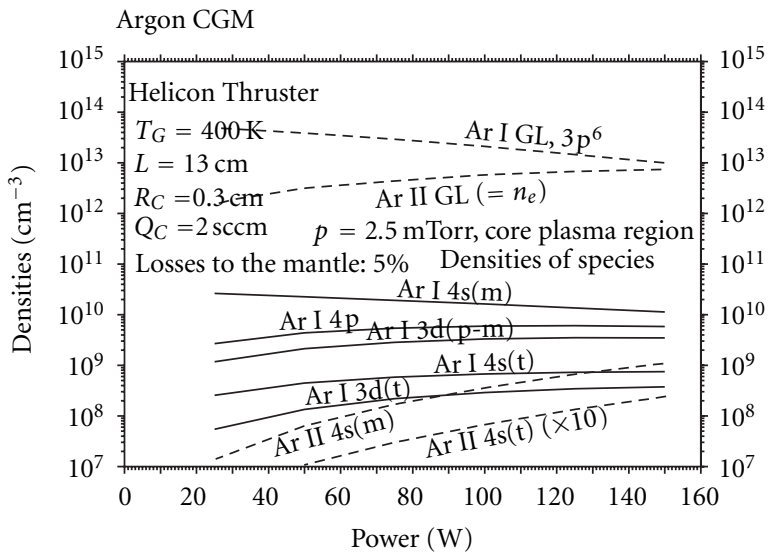

Figure 18: Calculated densities of $\mathrm{Ar}_{\mathrm{GL}}$, $\mathrm{Ar}$ excited species, and $\mathrm{Ar}^{+}$ in the core plasma region.

results obtained recently in a HT $[1,17]$. Figure 16 also shows the variation of $n_{e}$ passing from $5 \cdot 10^{12}$ to $9 \cdot 10^{12} \mathrm{~cm}^{-3}$, while it was about one order of magnitude lower in the mantle region. Note the high densities of Ar II $4 \mathrm{~s}(\mathrm{~m})$ (no factor) and of $4 \mathrm{~s}(\mathrm{t})$ (only a factor of 10) shown in Figure 16. These are much higher than those of the mantle case. Those results are in mutual agreement. Indeed, when more electrons are present, the collisional excitation increases, thus increasing the population of the excited levels. These excited states not only are departing from the neutral Ar GL, but also from the global metastable level $4 \mathrm{~s}(\mathrm{~m})$. However, the population of both of them is also increasing, because density increases. The ion population (hence the electron density) increases slowly, but the neutral density increases faster, and so the ionization percentage and the $T_{e}$ are decreasing as shown in the next Figure 17. This figure shows the plasma $T_{e}$ and the ionization percentage as a function of pressure. They both decrease of a factor of two and of nine, respectively, when the pressure passes from 2 to 10 mTorr. In the present example, the ionization percentage is nearly $35 \%$ for 2 mTorr, as it can be read in the right side of the figure.

Ionization percentage can be optimized by modifying the input parameters. For example, it is largely increasing when power increases, as it is illustrated in the following Figures 18 and 19. Figure 18 shows the variation of the densities of species as a function of the absorbed power which varies from 25 to $150 \mathrm{~W}$ for a pressure of $2.5 \mathrm{mTorr}$ and a core radius of $0.3 \mathrm{~cm}$. In Figure 19, we give the corresponding variation of $n_{e}, T_{e}$, and of the ionization percentage versus the absorbed power in the same conditions. Results similar to those shown for Figures 18 and 19 have also been obtained for various pressures. Experimental results described in [1, 17] are in agreement with these calculations.

\section{General Considerations and Trends}

When values of the necessary parameters are known, using CGM we obtain a sound modeling of the device and calculate the values of the plasma description quantities. Moreover, excited states species densities are calculated, both for neutral

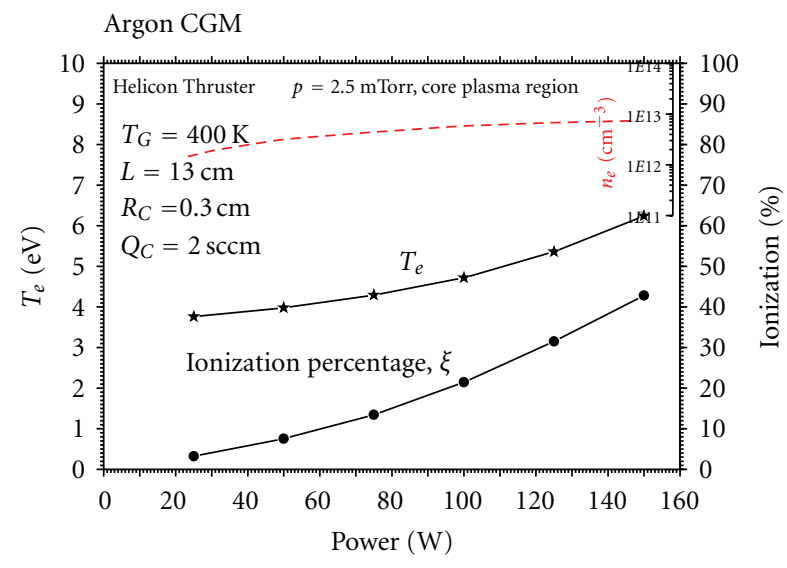

Figure 19: Calculated $n_{e}, T_{e}$, and ionization percentage versus absorbed power in the core plasma region.

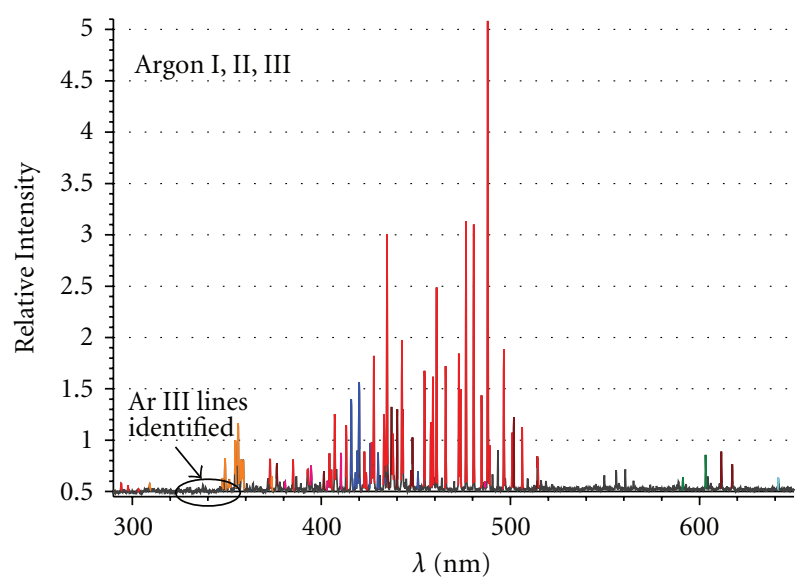

Identified lines from multiplets:

$$
\begin{aligned}
& \text { Blue: Ar I, 4s-5p } \\
& \text { Green: Ar I, 4p-4,5d } \\
& \text { Cyan: Ar I, 4p-6s } \\
& \text { Red: Ar II, 4s-4p } \\
& \text { Wine: Ar II, 3d-4p } \\
& \text { Pink: Ar II, 4p-5s } \\
& \text { Orange: Ar II, 4p-4d } \\
& \text { Grey: Other lines, including Ar III }
\end{aligned}
$$

Figure 20: A typical HT Ar spectrum in the 290 to $650 \mathrm{~nm}$ wavelength region. Main lines of Ar I and Ar II have been identified separately for each multiplet and marked with different colors.

and ionized species. The calculated excited states densities allow for convenient OES diagnostics, in conjunction of C-R models results $[1,17]$. This becomes possible even if the populations are very small. As an example, we give in Figure 20 the measured spectrum of a low-power HT, where the main Ar I and Ar II lines are identified. This spectrum has been used to evaluate the plasma $n_{e}$ and $T_{e}$. Note that the selected wavelength spectrum region allows for presence of intense Ar II lines near those of Ar I. Note that the most intense Ar I lines, the well-known "red lines" of the $4 \mathrm{~s}-4 \mathrm{p}$ multiplet, which belong to the $700-1000 \mathrm{~nm}$ region cannot be seen here. Inspection of Figure 20 shows the importance of the Ar I $4 s-5 p$ lines (blue) and of the Ar II $4 s-4 p$ ones (red) in 
TABLE 7: Sensitivity of various PR parameters for a pressure of 10 mTorr, including the configuration of the available experiment [15].

(a)

\begin{tabular}{lccrr}
\hline Parameters values & $T_{e}(\mathrm{eV})$ & $n_{e}\left(\times 10^{11} \mathrm{~cm}^{-3}\right)$ & $n_{4 \mathrm{~s}(\mathrm{~m})}\left(\times 10^{10} \mathrm{~cm}^{-3}\right)$ & $\xi(\%)$ \\
\hline$Q_{\mathrm{Ar}}: 5 / 50 / 500 \mathrm{sccm}$ & $2.51 / 2.51 / 2.51$ & $3.80 / 3.80 / 3.81$ & $2.68 / 2.69 / 2.71$ & $.20 / .20 / .20$ \\
$T_{\mathrm{GAS}}: 300 / 500 / 1000 \mathrm{~K}$ & $2.34 / 2.51 / 2.78$ & $3.90 / 3.80 / 3.57$ & $3.25 / 2.69 / 2.04$ & $.12 / .20 / .37$ \\
$R: 5 / 15.24 / 25 \mathrm{~cm}$ & $2.76 / 2.51 / 2.47$ & $12.46 / 3.80 / 1.89$ & $3.85 / 2.69 / 2.51$ & $.65 / .20 / .10$ \\
$L: 5 / 7.62 / 25 \mathrm{~cm}$ & $2.73 / 2.51 / 2.10$ & $3.81 / 3.80 / 3.03$ & $3.81 / 2.69 / 1.16$ & $.20 / .20 / .16$ \\
$P: 150 / 600 / 1000 \mathrm{~W}$ & $2.51 / 2.51 / 2.51$ & $1.30 / 3.80 / 5.34$ & $2.67 / 2.69 / 2.67$ & $.07 / .20 / .28$ \\
\hline
\end{tabular}

(b)

\begin{tabular}{lcccccccc}
\hline Parameters values & \multicolumn{2}{c}{$T_{e}$ ratios } & \multicolumn{2}{c}{$n_{e}$ ratios } & \multicolumn{2}{c}{$n_{4 \mathrm{~s}(\mathrm{~m})}$ ratios } & \multicolumn{2}{c}{$\xi$ ratios } \\
\hline$Q_{\mathrm{Ar}}: 5 / 50 / 500 \mathrm{sccm}$ & 1.00 & 1.00 & 1.00 & 1.00 & 1.00 & 1.01 & 1.00 & 1.00 \\
$T_{\mathrm{GAS}}: 300 / 500 / 1000 \mathrm{~K}$ & 1.07 & 1.11 & .97 & .94 & .83 & .76 & 1.67 & 1.85 \\
$R: 5 / 15.24 / 25 \mathrm{~cm}$ & .91 & .98 & 3.28 & .50 & .70 & .93 & .31 & .50 \\
$L: 5 / 7.62 / 25 \mathrm{~cm}$ & .92 & .84 & .31 & .80 & .71 & .43 & 1.00 & .80 \\
$P: 150 / 600 / 1000 \mathrm{~W}$ & 1.00 & 1.00 & 2.92 & 1.41 & 1.01 & .99 & 2.86 & 1.40 \\
\hline
\end{tabular}

the HT spectrum and illustrates the necessity to include the Ar I and Ar II 4s states in our CGM. A future improvement of our CGM would consist in adding more excited states, both for neutral argon and for the ion species, with priority to be given to configurations mentioned in the Figure 20 as resulting to identified lines.

Free parameters that we used in Parts (A), (B), and (C) of Section 5 are the same as those of two recent publications $[4,9]$. Because of the close dates of publication, it was never made possible to compare results of these publications previously. Our own model was used here, with the parameters describing the plasmas studied in both papers. Moreover, our model was applied to plasma conditions often considered in the plasma propulsion literature $[14,18]$.

Sensitivity of various parameters entering in our model is illustrated in Tables 7 and 8 for the plasma reactor case. In these tables, values of the main plasma description quantities, electronic temperature $T_{e}$, density $n_{e}$, Ar I metastable $n_{4 \text { sm }}$ density, and ionization percentage $\xi$, are given in four separate columns. The upper part (a) of the tables gives values corresponding to the parameters values, while in the lower part (b) the ratios of the upper part values are given, in order to ease comparison for example, with results from [9]. Parameters tested for their sensitivity are those previously reported in Section 5: $Q_{\mathrm{Ar}}, T_{\mathrm{GAS}}, R, L$, and $P_{\mathrm{abs}}$. In each row, one input plasma parameter is varying, while the other parameters remain at fixed values. Values of the latter are shown at the middle of the first column that gives the parameters values. Experimental conditions of [15], namely, $Q_{\mathrm{Ar}}=50 \mathrm{sccm}, T_{\mathrm{GAS}}=500 \mathrm{~K}, R=15.24 \mathrm{~cm}, L=7.62 \mathrm{~cm}$, and $P_{\mathrm{abs}}=600 \mathrm{~W}$, corresponding to the configuration reported in [9], have been used throughout. In Table 7, the pressure is fixed at 10 mTorr. In the last row, giving the plasma description variation with the absorbed power $P$, we observe that the $T_{e}$ and the $4 \mathrm{~s}(\mathrm{~m})$ population remain practically the same, about $2.51 \mathrm{eV}$ and $2.67 \cdot 10^{11} \mathrm{~cm}^{-3}$, correspondingly, with an absorbed power varying from $150 \mathrm{~W}$ up to $1000 \mathrm{~W}$. On the contrary, the same power increase results to both $n_{e}$ and $\xi$ values multiplication by a factor of about four.

In Table 7 and similar ones Tables 8 and 9, values less/more than 1.00 shown in the lower part of the table mean that the obtained results given in the upper part of the table are decreasing/increasing, accordingly, when the tested parameter is increasing.

Our 10 mTorr values shown in the lower part of Table 7 are in relative agreement with those of Table 7 of [9], even if the latter are valid for a mixture of $50 \% \mathrm{Ar}$ and $50 \% \mathrm{H}_{2}$. Note the ease of comparison of our results with the similar results given in [9]. In fact, the ratio of the total variation from the lower tested parameter value to the higher one can be simply obtained by multiplying the two ratios given in the two separate columns table for each ratio.

In order to obtain a glimpse of the situation in lower pressures, we provide Table 8, which is similar to Table 7 but for a pressure of $5 \mathrm{~m}$ Torr. Note that results shown in the lower part of Table 8 are overall very similar to those shown in Table 7, suggesting a smooth variation with pressure for the chosen parameters.

In the plasma thrusters core, we examine the parameters sensitivity by means of the Table 9 , illustrating the sensitivity of the main free parameters in typical core region conditions. In this table, similar to the two previous ones, the main plasma description quantities are the same with those studied in the PR case, that is, $T_{e}, n_{e}, n_{4 \mathrm{sm}}$, and $\xi$. Investigated parameters are analogous to those of Table 7 with a standard configuration of $Q_{\mathrm{Ar}}=2 \mathrm{sccm}, T_{\mathrm{GAS}}=400 \mathrm{~K}, R_{C}=0.3 \mathrm{~cm}$, and $L=13 \mathrm{~cm}$. The losses to the mantle region are varying around a standard value of $5 \%$. Here also, one of the six parameters is varied at each time, spanning the domains indicated in the table, while the others stay at their fixed values. A typical absorbed power of $100 \mathrm{~W}$ was chosen for this table, varying from 50 to $200 \mathrm{~W}$.

The lower part of Table 9 suggests that here $T_{e} / n_{4 \mathrm{~s}(\mathrm{~m})}$ are substantially increasing/decreasing with the absorbed power. Moreover, when power $P$ increases, $n_{e}$ increases about 
TABLE 8: As in Table 7 but for a pressure of 5 mTorr.

(a)

\begin{tabular}{lcccc}
\hline Parameters values & $T_{e}(\mathrm{eV})$ & $n_{e}\left(\times 10^{11} \mathrm{~cm}^{-3}\right)$ & $n_{4 \mathrm{~s}(\mathrm{~m})}\left(\times 10^{10} \mathrm{~cm}^{-3}\right)$ & $\xi(\%)$ \\
\hline$Q_{\mathrm{Ar}}: 5 / 50 / 500 \mathrm{sccm}$ & $2.97 / 2.97 / 2.98$ & $2.89 / 2.89 / 2.90$ & $2.64 / 2.64 / 2.66$ & $.30 / .30 / .30$ \\
$T_{\mathrm{GAS}}: 300 / 500 / 1000 \mathrm{~K}$ & $2.73 / 2.97 / 3.38$ & $3.03 / 2.89 / 2.70$ & $3.19 / 2.64 / 2.01$ & $.19 / .30 / .56$ \\
$R: 5 / 15.24 / 25 \mathrm{~cm}$ & $3.33 / 2.97 / 2.91$ & $9.88 / 2.89 / 1.44$ & $3.72 / 2.64 / 2.44$ & $1.02 / .30 / .15$ \\
$L: 5 / 7.62 / 25 \mathrm{~cm}$ & $3.26 / 2.97 / 2.47$ & $2.95 / 2.89 / 2.29$ & $3.58 / 2.64 / 1.27$ & $.31 / .30 / .24$ \\
$P: 150 / 600 / 1000 \mathrm{~W}$ & $2.97 / 2.97 / 2.97$ & $.96 / 2.89 / 4.18$ & $2.59 / 2.64 / 2.63$ & $.10 / .30 / .43$ \\
\hline
\end{tabular}

(b)

\begin{tabular}{lccccccc}
\hline Parameters values & \multicolumn{2}{c}{$T_{e}$ ratios } & \multicolumn{2}{c}{$n_{e}$ ratios } & \multicolumn{2}{c}{$n_{4 \mathrm{~s}(\mathrm{~m})}$ ratios } & \multicolumn{1}{c}{$\xi$ ratios } \\
\hline$Q_{\mathrm{Ar}}: 5 / 50 / 500 \mathrm{sccm}$ & 1.00 & 1.00 & 1.00 & 1.00 & 1.00 & .01 & 1.00 \\
$T_{\mathrm{GAS}}: 300 / 500 / 1000 \mathrm{~K}$ & 1.09 & 1.14 & .95 & .93 & .83 & .76 & 1.58 \\
$R: 5 / 15.24 / 25 \mathrm{~cm}$ & .89 & .98 & .29 & .50 & .71 & .92 & .29 \\
$L: 5 / 7.62 / 25 \mathrm{~cm}$ & .91 & .83 & .98 & .79 & .74 & .48 & .97 \\
$P: 150 / 600 / 1000 \mathrm{~W}$ & 1.00 & 1.00 & 3.01 & 1.45 & 1.02 & 1.00 & .50 \\
\hline
\end{tabular}

TABLE 9: Sensitivity of core region plasma parameters, for a pressure of 2.5 mTorr. Presentation of results follows this of Tables 7 and 8 .

(a)

\begin{tabular}{lcccc}
\hline Parameters values & $T_{e}(\mathrm{eV})$ & $n_{e}\left(\times 10^{12} \mathrm{~cm}^{-3}\right)$ & $n_{4 \mathrm{~s}(\mathrm{~m})}\left(\times 10^{10} \mathrm{~cm}^{-3}\right)$ & $\xi(\%)$ \\
\hline$Q_{\mathrm{Ar}}: 0.2 / 2 / 20 \mathrm{sccm}$ & $4.56 / 4.72 / 5.77$ & $5.89 / 5.77 / 5.17$ & $1.45 / 1.63 / 2.73$ & $22.5 / 21.4 / 17.0$ \\
$T_{\mathrm{GAS}}: 200 / 400 / 800 \mathrm{~K}$ & $3.91 / 4.72 / 6.14$ & $6.40 / 5.77 / 4.99$ & $2.01 / 1.63 / 1.28$ & $13.7 / 21.4 / 31.8$ \\
$R_{\mathrm{C}}: 0.15 / 0.3 / 0.6 \mathrm{~cm}$ & $9.96 / 4.72 / 3.39$ & $7.48 / 5.77 / 3.49$ & $1.61 / 1.63 / 1.37$ & $44.2 / 21.4 / 8.7$ \\
$L: 9 . / 13 . / 16 \mathrm{~cm}$ & $6.07 / 4.72 / 4.36$ & $7.18 / 5.77 / 4.93$ & $1.28 / 1.63 / 1.80$ & $38.3 / 21.4 / 15.5$ \\
Loss to mantle 3/5/8\% & $4.40 / 4.72 / 5.13$ & $6.12 / 5.77 / 5.34$ & $1.23 / 1.63 / 2.18$ & $24.6 / 21.4 / 18.1$ \\
$P: 50 / 100 / 200 \mathrm{~W}$ & $3.98 / 4.72 / 8.76$ & $3.17 / 5.77 / 8.12$ & $2.25 / 1.63 / 0.80$ & $7.5 / 21.4 / 61.39$ \\
\hline
\end{tabular}

(b)

\begin{tabular}{lccccccc}
\hline Parameters values & \multicolumn{2}{c}{$T_{e}$ ratios } & \multicolumn{2}{c}{$n_{e}$ ratios } & \multicolumn{2}{c}{$n_{4 \mathrm{~s}(\mathrm{~m})}$ ratios } & \multicolumn{2}{c}{$\xi$ ratios } \\
\hline$Q_{\mathrm{Ar}}: 0.2 / 2 / 20 \mathrm{sccm}$ & 1.04 & 1.22 & .98 & .90 & 1.12 & 1.68 & .95 \\
$T_{\mathrm{GAS}}: 200 / 400 / 800 \mathrm{~K}$ & 1.21 & 1.30 & .90 & .86 & .81 & .79 & 1.56 \\
$R_{\mathrm{C}}: 0.1 / 0.3 / 0.6 \mathrm{~cm}$ & .47 & .72 & .77 & .61 & 1.01 & .84 & .48 \\
$L: 9 . / 13 . / 16 \mathrm{~cm}$ & .78 & .92 & .80 & .85 & 1.27 & 1.10 & .49 \\
Loss to mantle $3 / 5 / 8 \%$ & 1.07 & 1.09 & .94 & .93 & 1.33 & 1.34 & .87 \\
$P: 50 / 100 / 200 \mathrm{~W}$ & 1.19 & 1.86 & 1.82 & 1.41 & .72 & .49 & .87 \\
\hline
\end{tabular}

a factor of two and half, while the ionization percentage is drastically increasing, here of about eight times. Part of those variations was also illustrated in Figures 18 and 19 of Section 6.

Moreover, Table 9 shows variations of the main parameters with the flow rate. We illustrate these variations by presenting in Figure 21 the variations of the densities of species and in Figure 22 the variation of $T_{e}$ and of the ionization percentage $\xi$, always as a function of flow rate. In both figures, the pressure is fixed at 2.5 mTorr, allowing for a small variation of the densities with the flow, together with a small decrease of $\xi$ concomitant to an increase of $T_{e}$.

Densities of various species obtained by our model compare favourably with available results both experimental and theoretical. However, some $T_{e}$ results were not in good agreement with existing theoretical results. With experimental ones, the discrepancy was occasionally higher. However, it

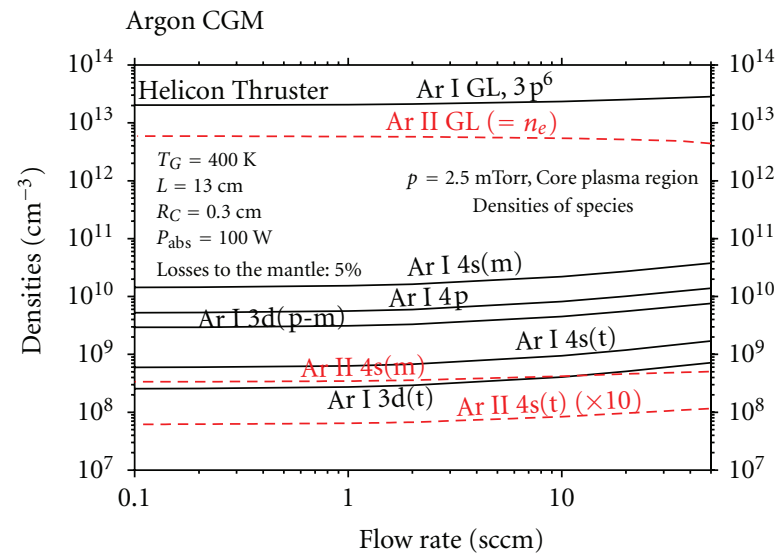

FIGURE 21: Variation of the densities of species as a function of the flow rate for a pressure of $2.5 \mathrm{mTorr}$. 


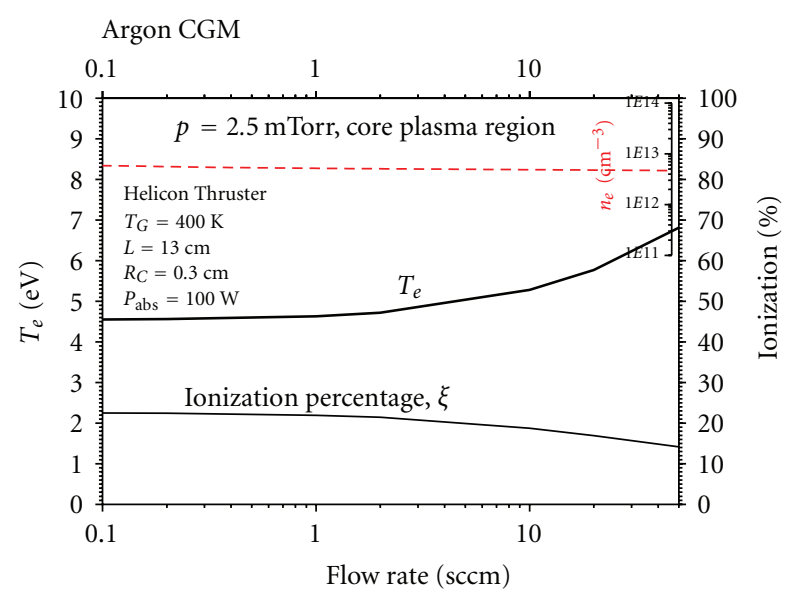

Figure 22: Variation of the electronic temperature and ionization percentage as a function of the flow rate, for a pressure of 2.5 mTorr.

has to be mentioned that measurements of $T_{e}$ present often considerable error bars.

Especially for the propulsion modeling, the 5\% of electron loss from the core to the mantle region is rather arbitrary, as this value is not yet sufficiently known. This situation calls for more experimental studies. Also, the suggested radius of the core region follows our OES measurements. The value chosen here has to be further investigated.

In general, there is evidently a limit in the parameters values, defining a limited region, where sound solutions of our model can be obtained. However, the main physical conditions encountered in common applications as those chosen and illustrated here are apparently largely contained within this limited region.

\section{Conclusions and Perspectives}

We formulated an extended Ar CGM, and we applied it to typical cases of plasma reactors and thrusters. Main plasma parameters characterizing the functioning of the studied device have been obtained for selected form factors. In order to describe the intrinsic plasma properties, sufficient atomic processes were included throughout. The inclusion of the latter in the model allows also for calculation of excited states population, which is of paramount importance in diagnostics and in optimization of the device. In general, comparisons of our results to the existing experimental results are satisfactory. However, more experimental results have to be obtained in the future, both for PR and for various types of EP devices, before arriving to a satisfactory optimization of these devices. Optical emission diagnostics of plasmas out of local thermodynamic equilibrium, a very common case in these devices, can be obtained by comparing experimental line intensities/populations with those of excited levels calculated by our C-R codes.

Description of general trends expected in plasmas encountered in various applications obtained with the help of our CGM has been presented in Section 7 and compared to those available in the literature. The obtained preview is useful not only for the study of physical properties belonging to these plasmas, but also in obtaining a glimpse of the improvements to be expected from possible variations of the used parameters. The latter possibility is of paramount importance in comparing the assets and drawbacks of a large variety of EP [18] types adapted for use in various space applications.

The CGM described here can be generalized in order to be applied also in the study of plasma reactors containing a mixture of species and in the study of thrusters fed with a variety of gases, including not only atomic ones, as is often the case with the rare gases feeding, but also with various molecular components considered as potential green propellants. In doing so, it is important to take correctly into account the decomposition of any molecular component. We have separately developed such a work for the case of $\mathrm{N}_{2}$ and $\mathrm{N}_{2} \mathrm{O}$ [6].

Furthermore, including a time-dependant variation of power, we can seek time-dependent resolution of the CGM equations system, in analogy with work done previously by Ashida et al. [19]. This feature will give a time-dependant information about the power absorption mechanism, explaining, for example, the helicon modes functioning. This is particularly important in the HT core case, where the electron heating takes place mainly in a reduced region situated near the axis, while for a SPT, the hot plasma region is wider.

Finally, straightforward generalizations can expand the application domain of our CGM in a number of important cases, of which we mention here this of plasma torch and of entry in various stellar atmospheres. We are currently working on this latter case $[20,21]$.

\section{Nomenclature}

A: $\quad$ Wall surface area of the device chamber

$A_{T}$ : $\quad$ Area of the thruster total section

$A_{C}: \quad$ Area of the core plasma section of the thruster

Ar C-RM: Argon collisional-radiative model

AtD: $\quad$ Atomic data

CGM: $\quad$ Complete global model

C-RM: Collisional-radiative model

$D_{j}$ : $\quad$ Neutral diffusion coefficient, $D_{j}=$ $\left(k_{B} T_{\mathrm{GAS}} \lambda_{j}\right) /\left(v_{j} M_{\mathrm{Ar}}\right)$

DXWALL, $j$ : De-excitation on the wall for a species $j$

EIONIZ: Ionization energy

ELAS: $\quad$ Elastic

EP: $\quad$ Electric propulsion

EXC: Excitation

GL: $\quad$ Ground level

GM: $\quad$ Global model

$h_{L}$ : $\quad$ Axial edge to center ratio of positive ion

density

$h_{R}$ : $\quad$ Radial edge to center ratio of positive ion

HT: $\quad$ Helicon thruster

IONIZ: Ionization

j: $\quad$ Species states index 


\begin{tabular}{|c|c|}
\hline$J_{1}:$ & First-order Bessel function \\
\hline$k_{B}:$ & $\begin{array}{l}\text { Boltzmann constant, } \\
k_{B}=1.3807 \cdot 10^{-23} \mathrm{~J} \cdot \mathrm{K}^{-1}\end{array}$ \\
\hline$k_{j}:$ & Processes rate coefficient involving state $j$ \\
\hline$L:$ & Plasma length \\
\hline$M_{\mathrm{Ar}}:$ & Argon mass \\
\hline$m_{e}:$ & Electron mass \\
\hline$(\mathrm{m}):$ & Metastable level \\
\hline$n_{e}:$ & Electronic density \\
\hline$n_{\mathrm{TOT}}:$ & Total argon species density \\
\hline OES: & Optical emission spectroscopy \\
\hline$p:$ & Pressure \\
\hline$P_{\mathrm{abs}}$ : & Absorbed power \\
\hline$(\mathrm{p}-\mathrm{m}):$ & Pseudometastable level \\
\hline PaBEs: & Particle balance equations \\
\hline PiC: & Particle in cell \\
\hline PoBE: & Power balance equation \\
\hline PR: & Plasma reactor \\
\hline$Q_{\mathrm{Ar}}:$ & Ar gas flow \\
\hline$R:$ & Plasma radius \\
\hline$R_{T}:$ & Radius of the thruster total section \\
\hline$R_{C}:$ & Radius of the plasma core \\
\hline RWALL, $\mathrm{Ar}^{+}$: & Recombination on the wall for $\mathrm{Ar}^{+}$species \\
\hline SPT: & Stationary plasma thruster \\
\hline SS: & Steady-state \\
\hline$T_{e}:$ & Electronic temperature \\
\hline$T_{G}, T_{\mathrm{GAS}}:$ & Gas temperature \\
\hline$T_{\text {ions }}:$ & Ions temperature \\
\hline$(\mathrm{t}):$ & Transitory level \\
\hline$u_{B}:$ & Bohm velocity, $u_{B}=\left(e T_{e} / M\right)^{1 / 2}$ \\
\hline$V:$ & Discharge volume \\
\hline$\varepsilon_{C}:$ & Collisional energy loss of the electrons \\
\hline$v_{j}:$ & $\begin{array}{l}\text { neutral mean velocity, } \\
v_{j}=\left(8 k_{B} T_{\mathrm{GAS}} / \pi M_{\mathrm{Ar}}\right)^{1 / 2}\end{array}$ \\
\hline$\gamma_{j}:$ & $\begin{array}{l}\text { Sticking coefficient for the neutral species } j \\
\text { on the wall surface; for Ar, } \gamma=1\end{array}$ \\
\hline$\lambda_{j}:$ & $\begin{array}{l}\text { Neutral-neutral species mean free path, } \lambda_{j}= \\
1 / n_{j} \sigma_{j-\text { Ar }} \text { for a cross section } \sigma\end{array}$ \\
\hline$\lambda_{i}:$ & Mean free path of ions \\
\hline$\Lambda:$ & Effective diffusion length \\
\hline$\xi$ & Ionization percentage \\
\hline$\xi^{\prime}:$ & Percentage of neutrals, $\xi+\xi^{\prime}=1$. \\
\hline
\end{tabular}

\section{Acknowledgment}

The authors are indebted to the unknown to them referee for recommendations which contributed to improve the paper.

\section{References}

[1] K. Katsonis, Ch. Berenguer, D. Pavarin et al., "Optical diagnostics of a low temperature argon thruster," in Proceedings of the 32nd International Electric Propulsion Conference (IEPC '11), Wiesbaden, Germany, September 2011, IEPC-2011-169.

[2] K. Katsonis, Ch. Berenguer, and M. Cornille, "Atomic data in Ar thruster multidimensional modeling and optical diagnostics," in Proceedings of the 31nd International Electric Propulsion Conference (IEPC '09), Ann Arbor, Mich, USA, September 2009, IEPC-2009-035.
[3] K. Katsonis, Ch. Berenguer, A. Kaminska, and M. Dudeck, "Argon $4 \mathrm{~s}$ and $4 \mathrm{p}$ excited states atomic data applied in ARCJET modeling," International Journal of Aerospace Engineering, vol. 2011, Article ID 896836, 15 pages, 2011.

[4] N. Kang, F. Gaboriau, S. G. Oh, and A. Ricard, "Modeling and Experimental Study of Molecular Dissociation in an Ar$\mathrm{N}_{2}$ ICP Discharge," Plasma Sources Science and Technology, vol. 20, no. 4, Article ID 045015, 2011.

[5] Ch. Berenguer, K. Katsonis, and D. Pavarin, "The resonant lines VUV transitions in rare gas plasma thrusters," in Proceedings of the 32nd International Electric Propulsion Conference (IEPC '11), Wiesbaden, Germany, September 2011, IEPC2011-170.

[6] K. Katsonis and Ch. Berenguer, " $\mathrm{N}_{2} \mathrm{O}$ propellant complete global model and related atomic data," Report DEDALOS 2012-3, Contribution to ESA ITT 7048 Project, unpublished.

[7] A. Lieberman and A. J. Lichtenberg, Principles of Plasma Discharges and Materials Processing, John Wiley \& Sons, Hoboken, NJ, USA, 2d edition, 2005.

[8] D. A. Shutov, S. Y. Kang, K. H. Baek, K. S. Suh, and K. H. Kwon, "Inductively-coupled nitrous-oxide plasma etching of parylene-C films," Journal of the Korean Physical Society, vol. 55, no. 5, pp. 1836-1840, 2009.

[9] A. T. Hjartarson, E. G. Thorsteinsson, and J. T. Gudmundsson, "Low pressure hydrogen discharges diluted with argon explored using a global model," Plasma Sources Science and Technology, vol. 19, no. 6, Article ID 065008, 2010.

[10] C. Lee and M. A. Lieberman, "Global model of $\mathrm{Ar}, \mathrm{O}_{2}, \mathrm{Cl}_{2}$, and $\mathrm{Ar} / \mathrm{O}_{2}$ high-density plasma discharges," Journal of Vacuum Science and Technology A, vol. 13, no. 2, pp. 368-380, 1995.

[11] Ch. Berenguer, K. Katsonis, P. Tsekeris, S. Cohen, M. Cornille, and R. E. H. Clark, "Measurement and evaluation of transitions probabilities of Ar I to III," in Proceedings of the European Group on Atomic Systems (EGAS '43), Fribourg, Switzerland, June-July 2011.

[12] A. V. Phelps, "Cross sections and swarm coefficients for nitrogen ions and neutrals in $\mathrm{N}_{2}$ and argon ions and neutrals in Ar for energies from $0.1 \mathrm{eV}$ to $10 \mathrm{keV}$," Journal of Physical and Chemical Reference Data, vol. 20, p. 557, 1991.

[13] E. G. Thorsteinsson and J. T. Gudmundsson, "A global (volume averaged) model of a nitrogen discharge: I. Steady state," Plasma Sources Science and Technology, vol. 18, no. 4, Article ID 045001, 2009.

[14] O. V. Batishchev, "Minihelicon plasma thruster," IEEE Transactions on Plasma Science, vol. 37, no. 8, pp. 1563-1571, 2009.

[15] J. T. Gudmundsson, "Experimental studies of $\mathrm{H}_{2} /$ Ar plasma in a planar inductive discharge ," Plasma Sources Science and Technology, vol. 7, no. 3, p. 330, 1998.

[16] T. Kimura and H. Kasugai, "Properties of inductively coupled rf Ar/ $\mathrm{H}_{2}$ plasmas: experiment and global model," Journal of Applied Physics, vol. 107, no. 8, Article ID 083308, 9 pages, 2010.

[17] D. Pavarin, F. Ferri, M. Manente et al., "Thruster development set-up for the helicon plasma hydrazine combined micro research project," in Proceedings of the 32nd International Electric Propulsion Conference (IEPC '11), Wiesbaden, Germany, September 2011, IEPC-2011-241.

[18] D. M. Goebel and I. Katz, Fundamentals of Electric Propulsion, John Wiley \& Sons, Hoboken, NJ, USA, 2008.

[19] S. Ashida, C. Lee, and M. A. Lieberman, "Spatially averaged (global) model of time modulated high density argon plasmas," Journal of Vacuum Science \& Technology A, vol. 13, p. 2498, 1995. 
[20] K. Katsonis and Ch. Berenguer, "A complete global model for He torch experiments and atmospheric entry study," in Proceedings of the 5th International Workshop on Radiation of High Temperature Gases in Atmospheric Entry, Barcelona, Spain, October 2012.

[21] Ch. Berenguer and K. Katsonis, "Modeling and diagnostics of $\mathrm{H} / \mathrm{He}$ mixture high temperature space plasmas," in Proceedings of the 5th International Workshop on Radiation of High Temperature Gases in Atmospheric Entry, Barcelona, Spain, October 2012. 

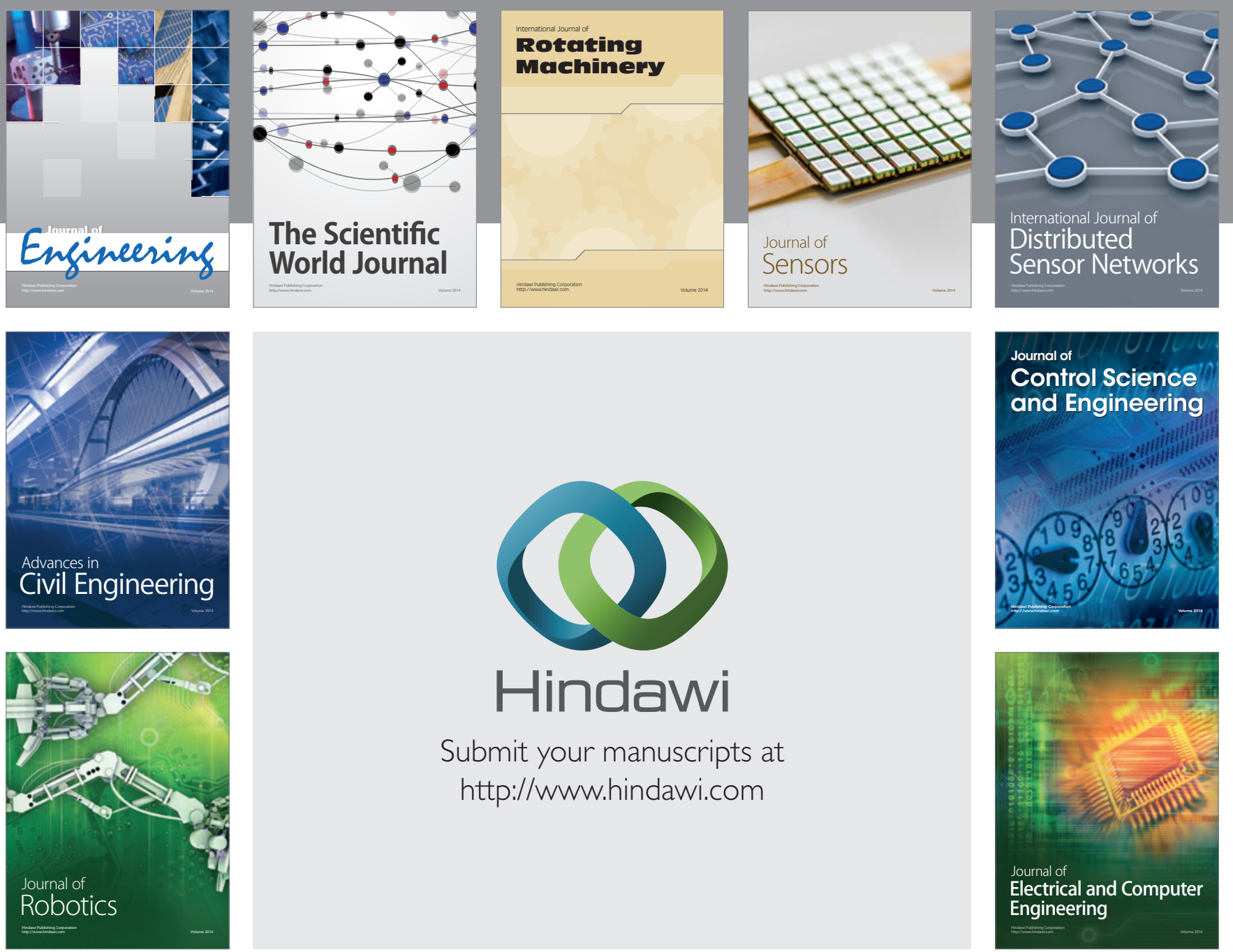

Submit your manuscripts at

http://www.hindawi.com
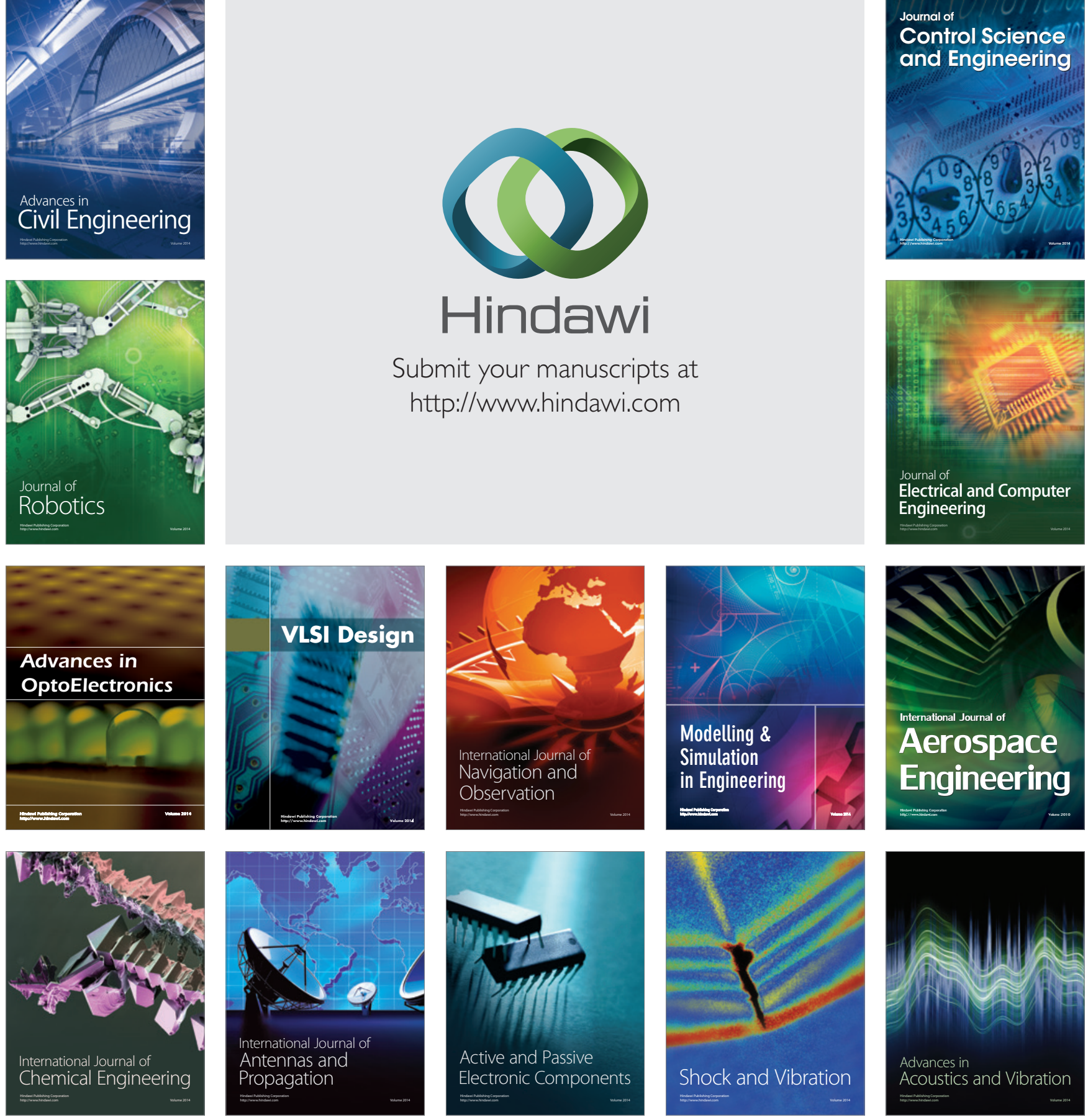